\title{
ATRIAL SEPTAL DEFECT
}

BY

\section{EVAN BEDFORD, CORNELIO PAPP, AND JOHN PARKINSON}

Received October 21, 1940

Patent foramen ovale and atrial (or auricular) septal defect (A.S.D.), though both characterized by an aperture in the atrial septum, are embryologically and pathologically different conditions.

Slit patency of the foramen ovale (to probe or even to pencil) is a commonplace in a normal atrial septum. As it should close during the first year of life, the patent foramen ovale is scarcely to be regarded as a congenital cardiac lesion, but rather as an anatomical variation of a pre-existent condition (Costa, 1931). It is present in 20-30 per cent of all necropsies (Thompson \& Evans, 1930; McGinn \& White, 1936; O'Farrell, 1938), and it is clinically silent. In exceptional circumstances an increase in the right atrial pressure during hypertensive cardiac failure (Marchal, Ortholan, \& Breton, 1939) or in mitral stenosis (Lutembacher, 1916, 1936) can open up the slit foramen ("widely patent") and determine or accentuate a terminal cyanosis. Pulmonary infarction may similarly enlarge the slit foramen and so facilitate the passage of a paradoxical embolus (Barnard, 1930; Thompson \& Evans, 1930; Jones, 1936; Löfgren, 1937; Hirschboeck, 1935; Koritschoner, 1936). Terminal cyanosis and paradoxical embolism are the only two events referable to this common conditiona slit or widely patent foramen ovale-and they are rare.

In contrast, an atrial septal defect is a malformation that is really congenital. The development of the atrial septum by the union of three incomplete septa, namely, the septum primum (or superius), the septum secundum, and the septum intermedium, leaves pervious first the foramen ovale primum and later the foramen ovale secundum. The latter, narrowed by the septum secundum and provided with a membrane by the septum primum, becomes the fossa ovalis.

Atrial septal defect is the most frequent of all congenital cardiac malformations (Table I). As a single lesion, it constitutes 7-25 per cent of all such cases. It is often associated with other congenital lesions-patent ductus arteriosus; ventricular septal defect; pulmonary stenosis; common atrioventricular canal (Rokitansky, 1875; Abbott, 1937; Roesler, 1934); transposition of the arterial trunks (Gibson \& Clifton, 1938), most often along with ventricular septal defect, with patent ductus arteriosus, or with both (Joules, 1934; Taussig, 1938); with rare venous abnormalities as pulmonary veins emptying into the right auricle (Rokitansky, 1875; Duff, 1938; Ash et al., 1939), or left 
superior vena cava (Chase, 1938). It may be complicated by complex lesions, e.g. Fallot's tetralogy (Feldman \& Snook, 1938), or by multiple congenital defects (our Case 6). Thus atrial septal defect may accompany almost any congenital lesions, but our paper deals with cases where it was the sole or the predominant congenital lesion.

TABLE I

Incidence of Atrial Septal Defect

\begin{tabular}{|c|c|c|c|c|}
\hline \multirow[b]{2}{*}{ Author } & \multirow[b]{2}{*}{$\begin{array}{l}\text { Consecutive } \\
\text { Necropsies }\end{array}$} & \multirow[b]{2}{*}{$\begin{array}{l}\text { Congenital } \\
\text { Heart Disease }\end{array}$} & \multicolumn{2}{|c|}{ Atrial Septal Defect } \\
\hline & & & Alone & $\begin{array}{l}\text { With other } \\
\text { Congenital } \\
\text { Heart } \\
\text { Lesions }\end{array}$ \\
\hline $\begin{array}{l}\text { Abbot (1937) } \\
\text { McGinn and White (1936) } \\
\text { Gibson and Clifton (1938) } \\
\text { Ingham (1938) } . .\end{array}$ & $\begin{array}{l}\overline{7500} \\
1950 \\
8314\end{array}$ & $\begin{array}{r}1000 \\
67 \\
105 \\
87\end{array}$ & $\begin{array}{l}72 \\
11 \\
23 \\
21\end{array}$ & $\begin{array}{r}301 \\
16 \\
12 \\
--\end{array}$ \\
\hline
\end{tabular}

It is the only congenital lesion that occurs at all commonly with mitral stenosis (Abbott, 1915; Lutembacher, 1916). Anatomical observations on this association have been reported by Louis (1826), Corvisart (1841), Mayne (1848), Peacock (1860), Martineau (1865), Rokitansky (1875), Griffith (1903), and Tylecote (1903). A review of 23 reported cases, with an added case, was published by McGinn and White (1933). Since then, Roesler (1934), Gibson and Roos (1935), Lutembacher (1936), Cossio and Berconsky (1936), Sailer (1936), Van Ruyven (1936), Cossio and Arana (1937), Battro and De La Serna (1937), and Taussig, Harvey, and Follis (1938) have contributed to the subject. Less common are rheumatic affections of the aortic, or of the aortic and mitral (both Jacobius \& Moore, 1938), or of all four valves (Taussig et al., 1938). Roesler (1934) believes that three-quarters of the reported cases that he studied had rheumatic valvular disease; among the 20 cases of Rokitansky (1875) 11 had mitral stenosis; and all the 4 cases of Taussig et al. (1938), had it. Among 10 cases of our own with necropsy, mitral stenosis was associated in 4 (Cases $7,8,9$, and 10). There is often adhesive pericarditis as well-the 11 cases of Rokitansky (1875), those reported by Battro and De La Serna (1937), by Cossio and Arana (1937), and by Cossio and Berconsky (1936), and our Case 8.

The frequency of rheumatic heart lesions is in sharp contrast with the rarity of subacute bacterial endocarditis though this is so common with other congenital heart lesions. Roesler (1934) and Taussig et al. (1938) even deny its existence; but Griffith (1906) early reported one case with localization on the pulmonary valves, and two appear in the statistics of Abbott (1937). The only one with localization on the septal defect is mentioned by Jacobius and Moore (1938); in our Case 4 the vegetations were in the left auricle but involved neither the defect nor the mitral valve. 
The following account is based on a series of 53 cases of atrial septal defect. In 10 the diagnosis was verified by necropsy, and in the rest characteristic clinical and radiological findings seemed to place it beyond reasonable doubt. The age and sex incidence are shown in Table II. We first made this clinical diagnosis in 1933 (Case 3); this patient died in 1935, and the diagnosis was confirmed at necropsy. The remaining cases represent our joint experience up to date, after excluding several doubtful ones.

TABLE II

Age and Sex Groups in 53 cases of Atrial Septal Defect (8 with Mitral Stenosis)

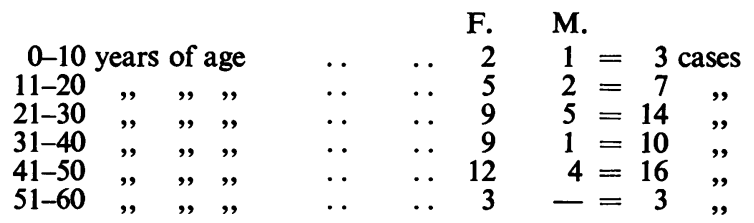

\section{Pathology}

Of the 10 patients with necropsy control, A.S.D. was the only lesion in 5: it was associated with mitral stenosis in 4; and with ventricular septal defect, slight patency of the ductus arteriosus, and slight coarctation of the aorta in Case 6.

The age of death was mostly between 30 and 50. The oldest in our series was 46 when she died; the oldest reported, 77 (Tarnower \& Woodruff, 1936). The prevalence of females in our necropsy series is even more striking (4:1) than is that of Roesler (1934) $(3: 2)$. The cause of death was exceptional in two: subacute bacterial endocarditis in one (Case 4) and paradoxical embolism in the other (Case 7) (see Tables II and III).

\section{TABLE III}

Cause of Death in 10 Necropsy Cases (4 with Mitral Stenosis

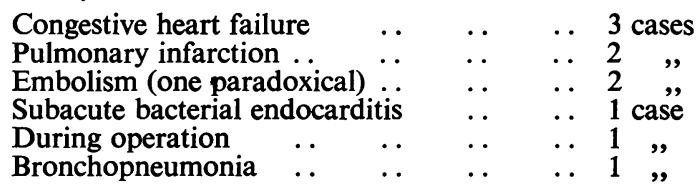

The heart was always greatly enlarged, often huge and square in shape; its weight was $930 \mathrm{~g}$. (Case 9), $540 \mathrm{~g}$. (Case 7) and $540 \mathrm{~g}$. (Case 4). The right cavities composed the anterior surface and the apex of the heart (Figs. 1 and 2A) and the bulk of the organ. The circumference of the right ventricle was 22 $\mathrm{cm}$. and that of the left $12 \mathrm{~cm}$. (Case 8 ), the proportion between right and left cavities was described as 3:1 (Case 2), and the left ventricle and auricle appeared as an appendix of a huge heart formed by the right cavities and the conus (Case 9). The external aspect of the heart was not very different when mitral stenosis co-existed, but on the whole the heart appeared more voluminous and the disproportion between right and left cavities greater than when it was 


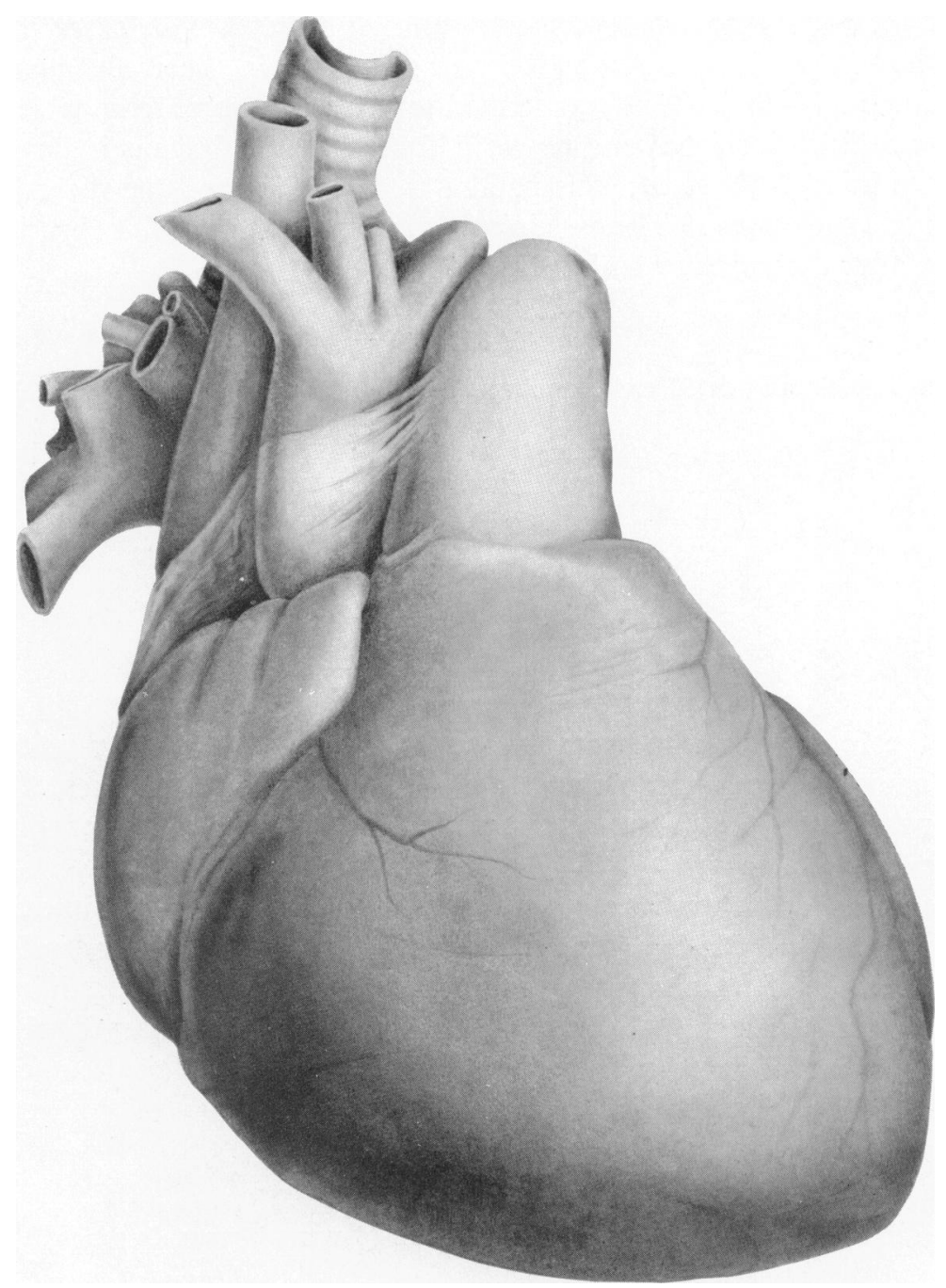

FIG. 1.-Atrial septal defect (A.S.D.); Case 3. The anterior surface of the heart, including the apex, is formed by the right chambers and only a small strip of the left ventricle is seen. The pulmonary artery is greatly enlarged; the aorta is normal (cf. Fig. 6).

absent. On the cut surface the right ventricle showed much hypertrophy and dilatation (Figs. 2C and 3). Dilatation was greater with co-existent mitral stenosis and with long-standing failure; hypertrophy with the others. The thickness of the right ventricle was $1 \cdot 3-1 \cdot 7 \mathrm{~cm}$. (Case 1 ) and $1 \mathrm{~cm}$. (Case 4 ). The left ventricle was of normal thickness (except in Case 6 with ventricular septal defect, where slight hypertrophy was present), but it appeared thicker than the right in Cases 8 and 9 with extreme right ventricular dilatation. Great dilatation of the right auricle was the rule. It was as large as a fist (Case 9), it was three times the size of the left auricle (Case 3), its diameters were $16 \mathrm{~cm}$. by $12 \mathrm{~cm}$. (Case 8 ), or it contained ante-mortem clots responsible for paradoxical embolism (Case 7). The tricuspid ring, mostly dilated and incompetent, had a circumference of 


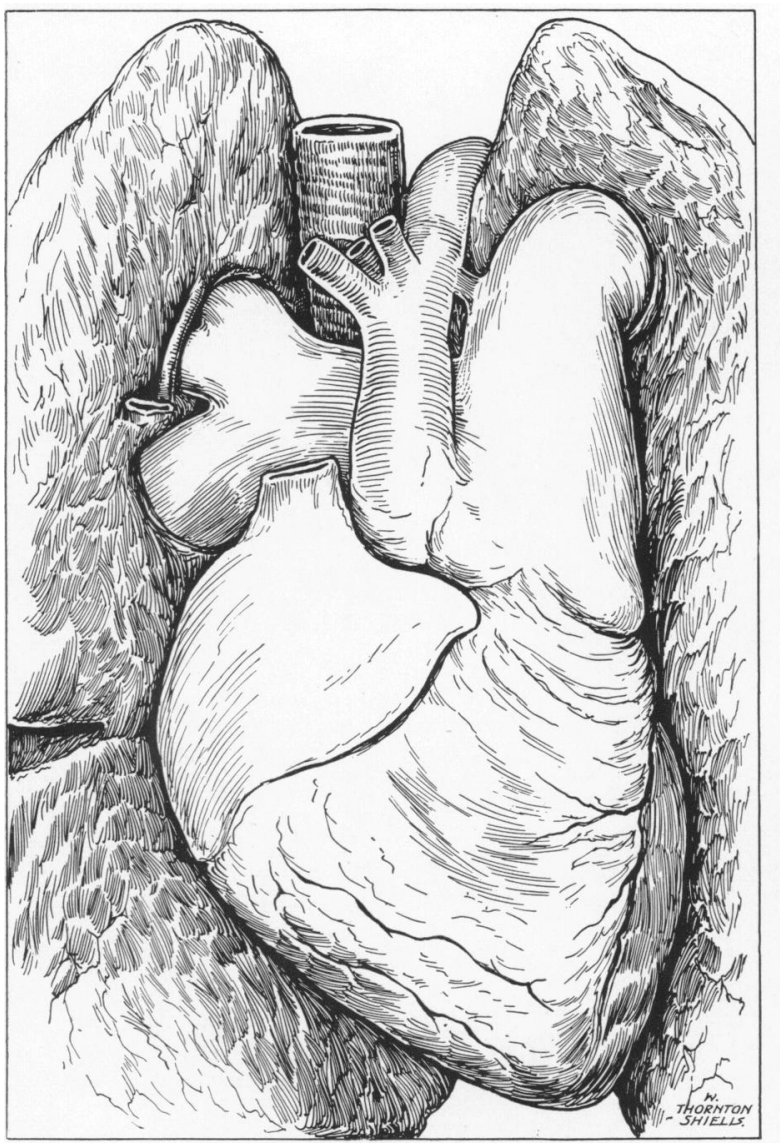

A

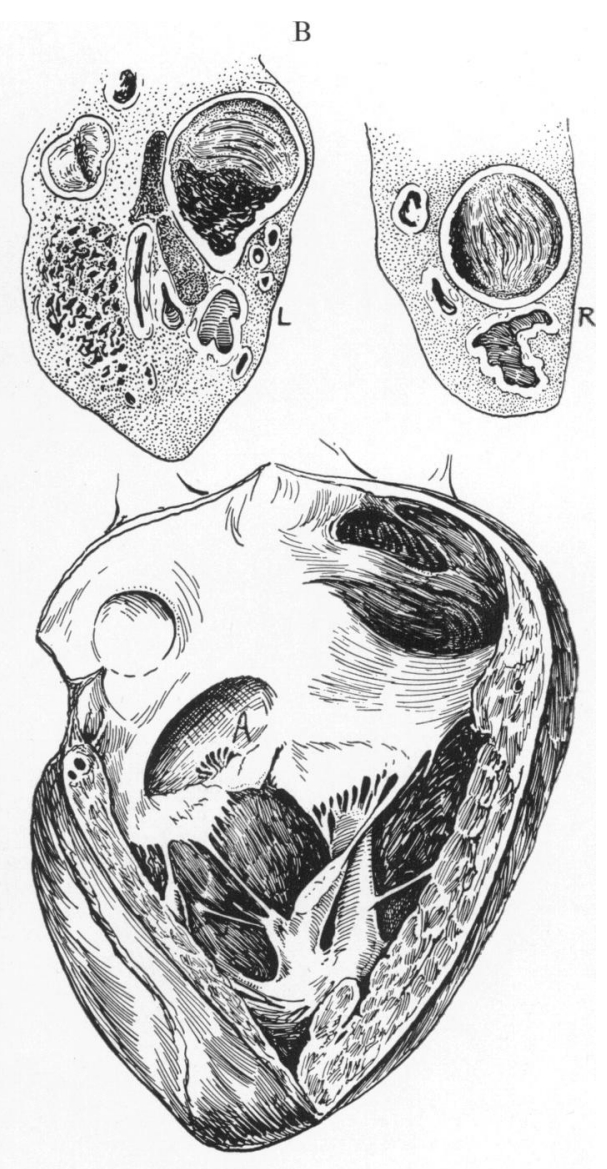

$\mathrm{C}$

$16 \mathrm{~cm}$. (Case 8), a diameter of $8.9 \mathrm{~cm}$. (Case 9), or permitted the passage of four fingers (Case 10). The left auricle was normal except in two cases with mitral stenosis and fibrillation, where it was moderately dilated and had a diameter of $9 \mathrm{~cm}$. (Case 8). The mitral stenosis was of buttonhole type in Cases 7, 9, and 10 (Fig. 5); the valve aperture was $2 \mathrm{~cm}$. by $1 \mathrm{~cm}$. in Case 8 .

A disproportion comparable with that between the right and left ventricle existed between the pulmonary artery and the aorta. Except once (Case 9) where the pulmonary artery was normal (though the conus was very large) (Fig. 4), the pulmonary artery and its branches were always greatly dilated (Figs. 1 and $2 \mathrm{~A}$ ). The circumference of the pulmonary trunk was $10 \mathrm{~cm}$. (Case 10) 


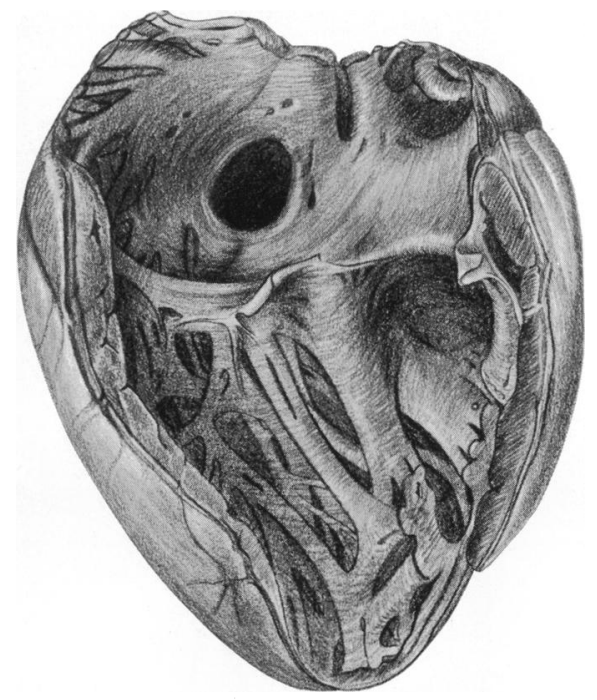

FIG. 4.-A.S.D. with mitral stenosis; Case 9. Heart, anterior view. Huge right ventricle and conus, greatly enlarged right auricle. Left ventricle invisible from the front. Pulmonary artery small, aorta normal (cf. Fig. 16). 
and $8.5 \mathrm{~cm}$. when that of the aorta was of $5.5 \mathrm{~cm}$. (Case 4). The diameters of the pulmonary artery and aorta at their base were 5.5 and $2.5 \mathrm{~cm}$. (Case 1), 4.5 and $3.0 \mathrm{~cm}$. (Case 3), and 4.5 and $2.3 \mathrm{~cm}$. (Case 10) respectively. The aorta was recorded as small in 7 cases (Cases 1, 2, 5, 6, 7, 9, and 10); and the pulmonary branches, except in Case 9, were larger than the descending aorta (Fig. 2A). The proportion was $3 \cdot 5$ and $2 \mathrm{~cm}$. (Case 3 ), and $2 \cdot 7$ and $1 \cdot 3 \mathrm{~cm}$. (Case 10). The right and left pulmonary branches were equal in diameter with the exception of Case 3 where the right was larger than the left $(3.5$ and $2.7 \mathrm{~cm}$.). The pulmonary artery and its branches were nearly always thickened; severe atheroma was present with extensive old and recent thrombosis in Case 1 (Fig. 2B), and in a lesser degree in Cases 5, 6, and 8. Pulmonary infarction was found in Cases 1, 7, and 8; its part in producing paradoxical embolism in Case 7 seems as obvious as in other reported cases.

The defect in the atrial septum was of oval or circular shape; its diameter was 2.3 by $5 \mathrm{~cm}$. (Case 1), $1.5 \mathrm{~cm}$. (Case 3), 3.5 by $2.5 \mathrm{~cm}$. (Case 4 ), $5 \mathrm{~cm}$. (Case 5), 3 by $2 \mathrm{~cm}$. (Case 6), 1 by $0 \cdot 8 \mathrm{~cm}$. (Case 7), 7 by $4 \mathrm{~cm}$. (Case 8 ), 2 by $3 \mathrm{~cm}$. (Case 9), 5 by $3.5 \mathrm{~cm}$. (Case 10). Multiple defects were found in Case 6, and a strand of fibrous tissue divided the large defect in Case 8. The atrial septum was almost absent in Case 10 (Fig. 5) and only a rudiment

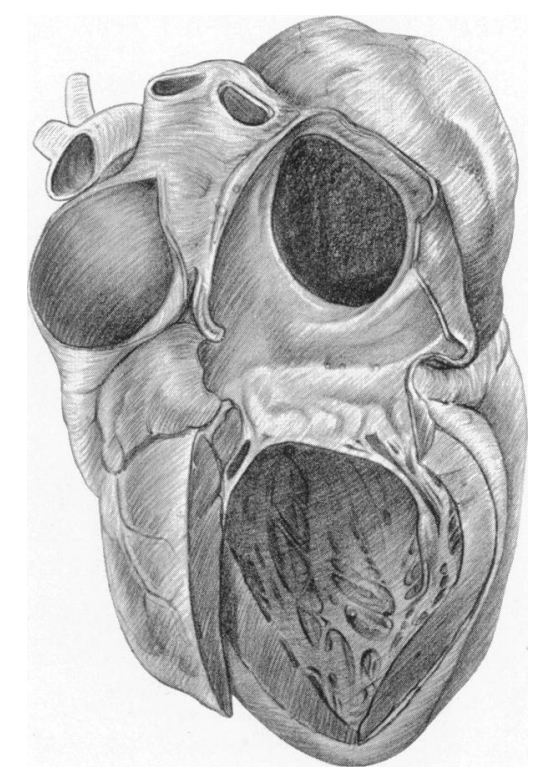

FIG. 5.-A.S.D. with mitral stenosis; Case 10. Posterior view of the heart with left ventricle, left auricle, and pulmonary artery opened; almost complete absence of atrial septum The inner surface of the greatly enlarged right auricle is seen through the defect; the pulmonary artery is much dilated; the mitral cusps are fused and thickened.

bordered the aperture at its upper margin. This type of defect is due to an arrest in the early stage of formation of the septum primum (Group 1 of Costa, 1931). The defect in the inferior part of the septum as far as the ventricular septum, associated with an imperfection of the tricuspid valve in Case 1 (Fig. 2C), represents the persistence of the foramen primum due to 
an agenesis of the septum intermedium (Group II of Costa, 1931). In all the others the site of the defect was the fossa ovalis, or the upper part of the septum as in Case 2 (Fig. 3). These belong to the commonest group of malformations (Group IV of Costa, 1931) due to agenesis of the septum secundum, which fails to restrict the foramen ovale, and of the septum primum in its latest stage of development, i.e. the formation of the membrane. In other words, there is absence of the valve membrane and the limbus in true A.S.D., at the site of the fossa ovalis. The confusing term of "widely patent foramen ovale" often used for this condition should be reserved for the distension of a functionally patent foramen ovale without congenital septal defect.

The anatomical division of Costa (1931) and that of Routier (1939) into early and late defects has less pathological importance if it is believed that the pathological alterations are related to the size of the defect (Cruveilhier, 1852; Roesler, 1934) and not to its embryological type. Case 7 with the smallest defect in our series $(1 \mathrm{~cm}$. by $0.8 \mathrm{~cm}$.) died suddenly at a time when the heart condition had improved with rest and digitalis; and Case 3 with a defect of $1.5 \mathrm{~cm}$. is our oldest necropsy case. But the pathological alterations in these two hearts were quite comparable in degree with those of Cases 5,8 , and 10 with large defects.

\section{Clinical Features}

Dyspncea of some degree is the rule though it may be absent. A fair capacity for exertion, even with an enlarged heart often on the verge of failure, has been recognized as a sign of a certain importance (Roesler, 1934; Van Ruyven, 1936), since Firket (1890) reported the case of a woman who died when she was 74 after having had 11 pregnancies. Our Case 26 had 5 children; she is now 50 and only recently showed the first signs of failure; Case 32 was a golf champion a few years before when first seen; Case 53 (42 years old), with mitral stenosis, is still an active housewife, and so is Case 20.

Pain. Sternal pain was absent in all but one (Case 3) of our patients. One had left mammary pain, and another had epigastric pain due to the congested liver.

Under-development, small build, or frail constitution was emphasized by Roesler (1934), Leech (1935), Tarnower and Woodruff (1936), Abbott (1937), and Taussig et al. (1938); but we think too much has been made of the association though it occurs (Table IV), and also of associated mongolian idiocy and other developmental defects (Abbott, 1937) which are absent in our series.

Cyanosis is an inconstant sign (Laubry \& Pezzi, 1921; Pezzi, 1937), and its presence generally implies failure or a greatly enlarged heart about to fail. The type of cyanosis found in A.S.D., first described by Bard and Curtillet (1889) as cyanose tardive, is due to a reversal of the flow left to right to right to left, following right ventricular failure. In latent failure the shunt is only on effort and cyanosis is absent during rest. Effort cyanosis, as could be produced in our Cases 2,11,18,22, and 50, is indeed more significant than cyanose tardive which may be no more than the cyanosis of co-existent cardiac failure. The 
presence of intense cyanosis with the signs of A.S.D. and without failure should suggest a combination with other congenital defects, such as Fallot's tetralogy, common atrioventricular canal, or transposition of the arterial trunks in a child (Case 33), or a complicating thrombosis of the pulmonary branches in an adult (Case 1). Clubbing in our series was infrequent and always linked with cyanosis. The clinical features and cardiac signs are given in Table IV.

TABLE IV

Clinical Features

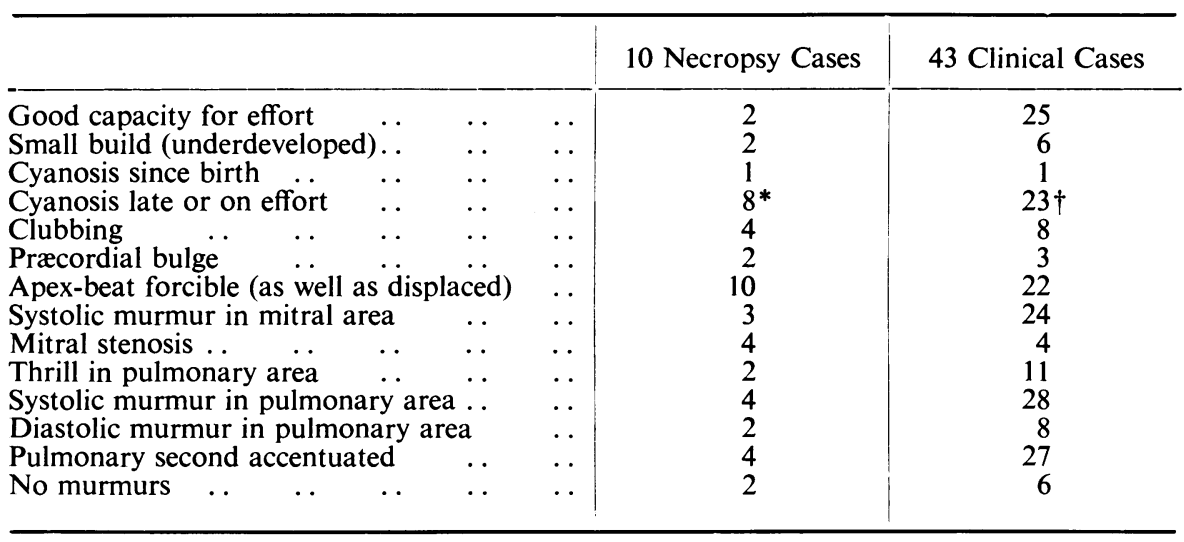

* All with failure.

$\dagger 8$ with failure.

Cardiac signs.-(1) Pracordial bulge is simply a sign of early and pronounced cardiac enlargement, so that its presence (about 10 per cent of our series) is not specific.

(2) The apex-beat was both displaced and forcible in more than two thirds of our series. It was displaced to the left in 27 cases, reaching the anterior or middle axillary line in 14 of these, and as low as the sixth space in 8 of these 14 . Though this sign commonly indicates left ventricular enlargement, it is here produced by the enlarged right ventricle, which pushes the left backwards, and itself enlarges towards the left to form the apex-beat. As Roesler (1934) maintains, the displaced and often forcible apex-beat, so widely accepted as an index of left ventricular enlargement, must be regarded as an important sign of A.S.D., in the absence of aortic valvular disease or hypertension.

(3) Heart sounds and murmurs.-There may be no audible physical signs (in 8 of our cases) or such various signs as a systolic murmur in the mitral or pulmonary area or in both. If so, the murmur is usually (but not always) more intense at the pulmonary area where a systolic pulsation or even a thrill may also be felt. The pulmonary second sound is commonly accentuated maybe to reach a metallic character, and it is often palpable. It was followed in 10 of our 53 cases by a soft, blowing, diastolic murmur. The presence of these signs in the pulmonary area in mitral stenosis may suggest a co-existent septal defect though they may be found on rare occasions in advanced mitral stenosis (Graham Steell murmur).

The variety of the auscultatory findings and their absence in typical cases 
make it difficult to assign them, as several authors have done (Gibson \& Roos, 1935; Leech, 1935; Taussig et al., 1938), to the defect itself. The murmur so produced should be a short presystolic murmur due to contraction of the left auricle, which could hardly be audible on the anterior surface of the heart because its transmission would be hindered by the hypertrophied ventricle (Laubry \& Pezzi, 1921). But the systolic thrill and murmur so often audible over the pulmonary area can be readily explained by the dilatation of both conus and pulmonary artery giving rise to a relative stenosis of the lesser distended pulmonary ring (Cossio et al., 1938). Whirling movements of the blood in a dilated pulmonary conus are thought to be responsible for the diastolic murmur in this area by Routier and Heim de Balsac (1938), who reject the possibility of a functional incompetence of the pulmonary valve. We believe that there can be such pulmonary incompetence (Cases 1 and 6). The tricuspid orifice is so often enlarged that it may account for the systolic murmur heard at the apex, here formed by the right ventricle.

\section{Radiological Features}

Since Assmann (1928) first established the chief radiological sign in atrial septal defect, i.e. the enlargement of the pulmonary artery and of its branches, important contributions have been made to the subject by Dressler and Roesler (1930), Roesler (1934), Battro et al. (1937), Cossio and Arana (1937), Levesque et al. (1937), Pezzi (1937), Routier et al. (1938), Heim de Balsac (1939), Joly (1939), Laubry et al. (1939), and Roesler (1939).

Radiological investigation was conducted in 51 of our series, i.e. in all excepting 2 of the 10 necropsy cases who were too ill for this (see Table V).

TABLE V

Radiological Features

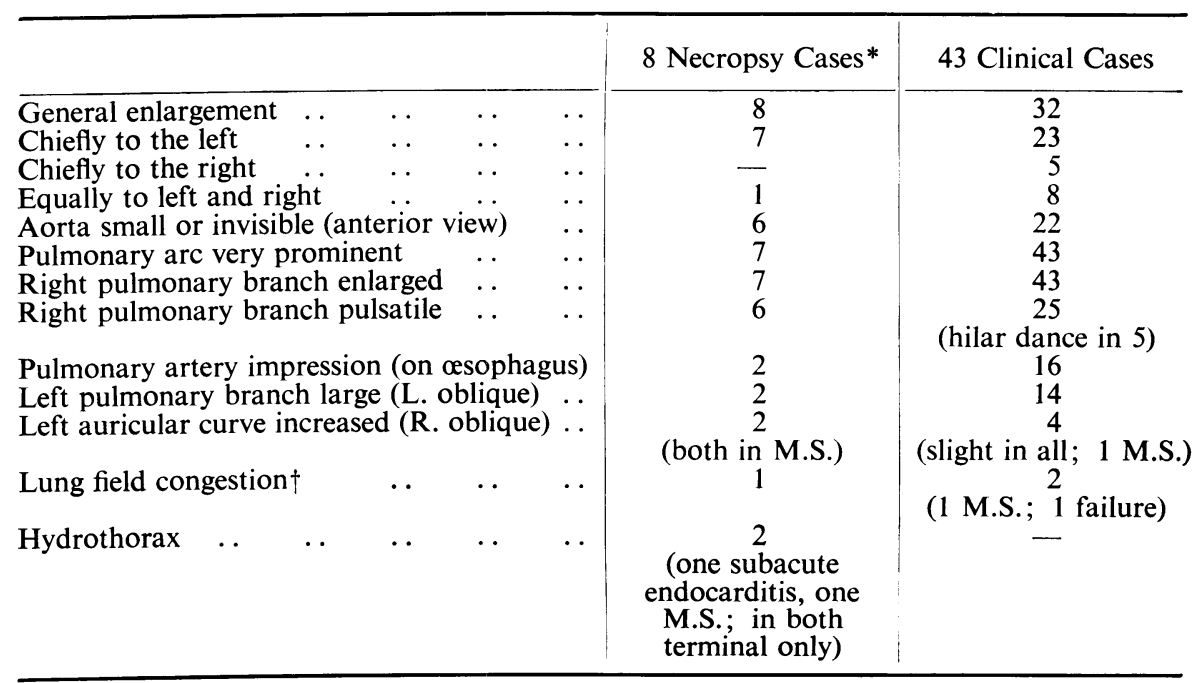

* Two cases had no X-ray examination.

$\dagger$ Clinical signs of failure were present in all necropsy cases and in 8 of the 43 clinical cases. M.S. $=$ mitral stenosis. 
In the anterior position the heart was almost invariably seen to be enlarged. Enlargement to the left was pronounced in 30 cases, and in 6 of them the convexity of the left heart border was displaced as far as the left chest border. Enlargement to the right was pronounced in only 14, and in 6 of them more than to the left. This is opposed to the findings of Battro et al. (1937) and Cossio and Arana (1937), who hold that enlargement to the right is a capital sign of A.S.D. We think that the right auricle enlarges partly to the front and to the left, contributing to the displacement of the enlarged right ventricle (to the left), because we sometimes found at necropsy gross enlargement of the right auricle without any striking enlargement to the right on their radiographs. The right auricular border may be elongated (Fig. 10), and this, of course, happens more when there is mitral stenosis (Figs. 14 and 16). It is the enlarged right ventricle that determines the convex and prominent left border of the heart and simulates so closely left ventricular enlargement (Fig. 6). The rounded apex seldom merges into the diaphragm but stands out distinct; yet the total appearance is rarely that of a "sabot-shaped" heart, the left border being placed too nearly vertical for this (Figs. 6, 7, 9, and 10), though all our $\mathrm{X}$-ray figures were taken in deep inspiration.

The extreme, almost aneurysmal, bulging of the pulmonary arc gives the heart its typical aspect, and it was the dominant sign in all our cases (Figs. 6, 7, 8, 9, and 10)-except one (Fig. 16); its contour was evenly rounded, and we could not identify any double curve due to combination of the left branch with

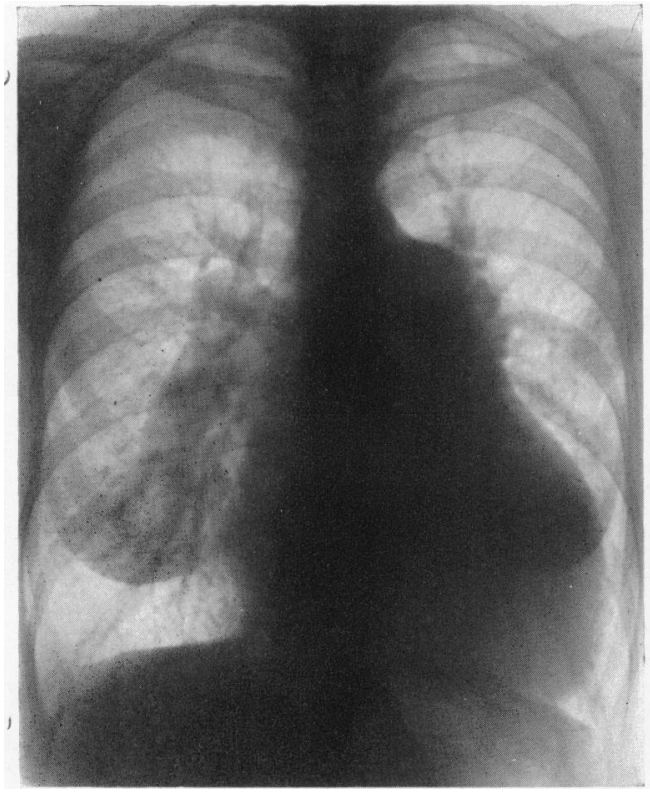

FIG. 6.-A.S.D.; Case 3 (necropsy control). Anterior view. Cardiac enlargement with displaced and convex left border due to the right ventricle (see Fig. 1), bulging of the pulmonary artery, enlarged right pulmonary branch. Note absence of lung congestion in this and similar figures. Breast shadows.

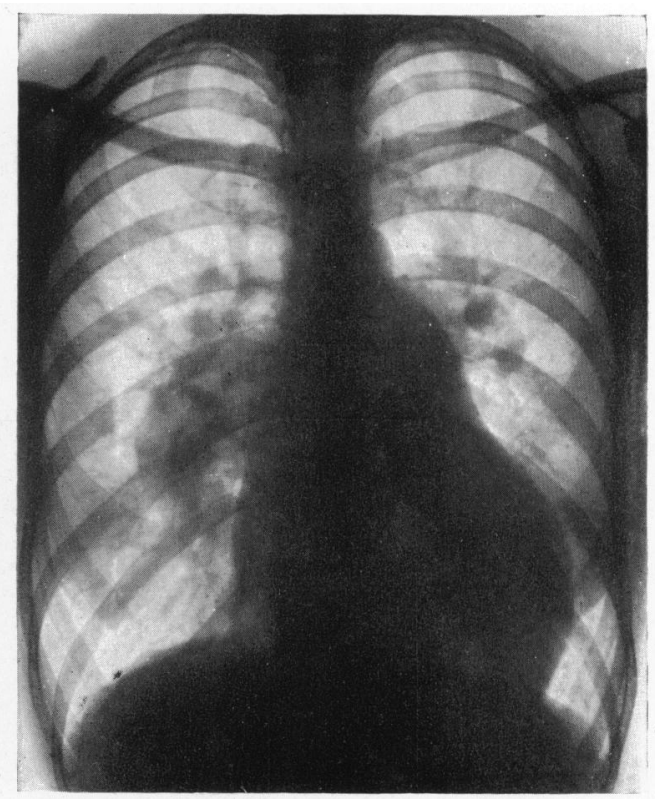

Fig. 7.-A.S.D.; Case 40. Similar to Fig. 6, but aortic knob visible above dilated pulmonary artery. Great dilatation of right pulmonary branch ("comma shaped"), and a constellation formed by smaller branches. 

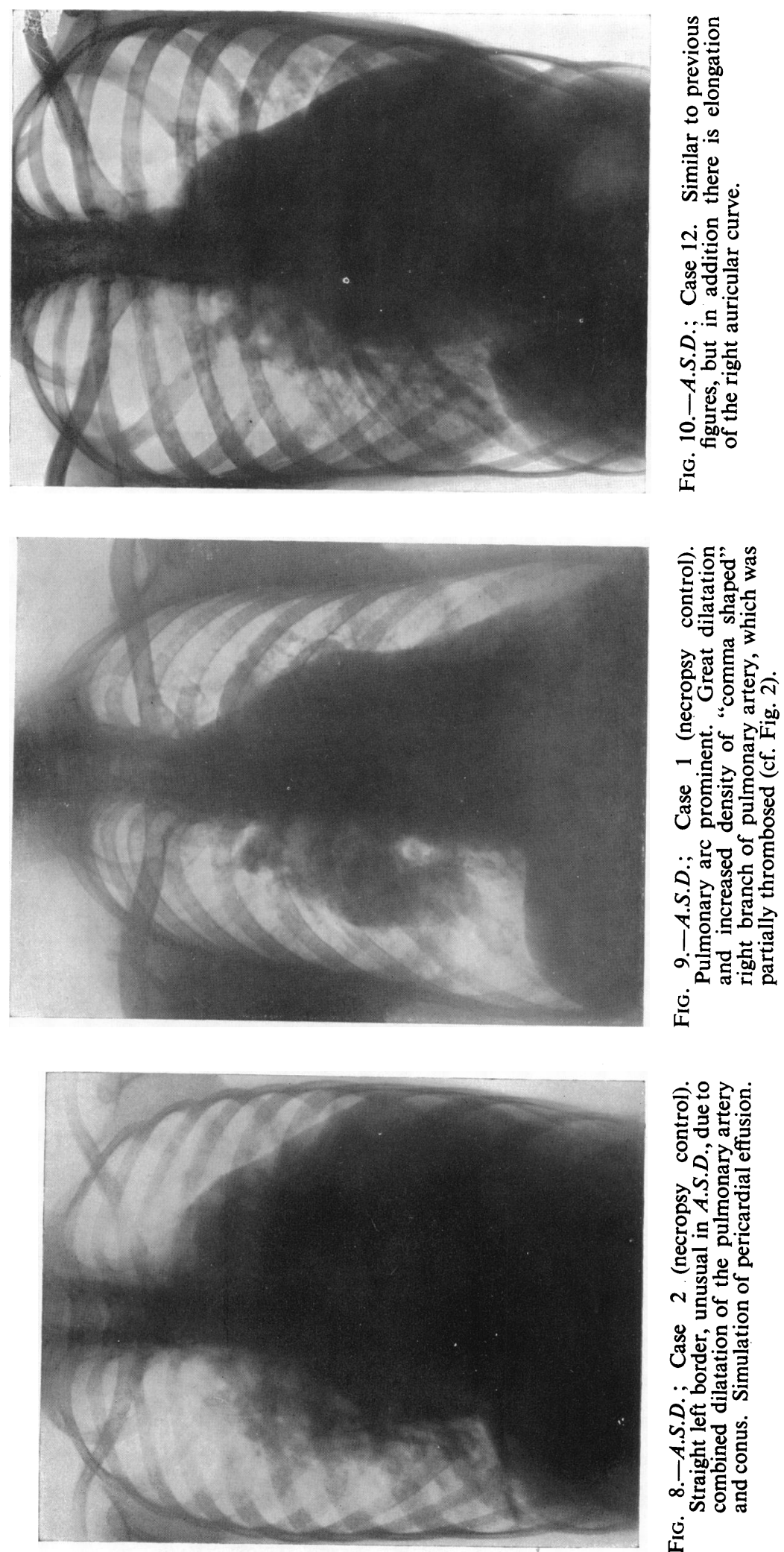
the main stem as described by Robb and Steinberg (1939), though we think it very possible that the pulmonary arc may be exaggerated by such a combination. The conus of the right ventricle was scarcely prominent, and a straight left border-comparable with that of mitral stenosis-was only seen once (Fig. 8). The main pulmonary branches were always enlarged. In the anterior position the right branch formed a large, dense, defined and often comma-shaped shadow (Figs. 7 and 9). It contrasted with the clear lung fields, especially as pulmonary congestion and hydrothorax were almost always lacking even with congestive failure (see Table V). The pulmonary artery often pulsated visibly, particularly its right branch, producing the "hilar dance" described by Pezzi $(1925,1932)$ as a radiological sign of pulmonary incompetence. Yet we saw it in cases without pulmonary incompetence, and sometimes failed to see it when pulmonary incompetence was noted (pulmonary diastolic murmur). Such great pulsation is not always seen, though occasionally a lack of pulsation with increased density implies local thrombosis (Fig. 9).

The aortic knob was small or wanting (anterior view) in 28 of the 51 cases, and was normal in the others.

In the right (I) oblique position, the enlarged pulmonary artery with the conus increases the width of the heart shadow in its upper third and forms a squarish mass that bulges both to the front and to the back (Fig. 11). An oval, pulsating, denser shadow can often be discerned within it, in front of the aorta and just above the right bronchus; it is the "pulmonal fleck" (Schwedel \& Epstein, 1936) and corresponds to the bifurcation and the right branch of the pulmonary artery seen in cross section. The straightness of the posterior border in its lower (left auricular) position, is a characteristic of the picture, and barium in the œsophagus will emphasize it. The aortic impression on the œsophagus is usually small and sometimes it is absent. In contrast, below it may be a large, deep impression - an exaggerated pulmonary artery impression (Parkinson \& Bedford, 1931). The course of the œsophagus in the left auricular region is straight or slightly curved, quite unlike that featuring mitral stenosis (Figs. 12 and 15). There were, however, 6 cases in which this left auricular curve was more pronounced though never extreme. In 2 of them, necropsy showed mitral stenosis and some enlargement of the left auricle; of the other 4, one had also mitral stenosis clinically, but the remainder had no signs of it. It is admitted that general cardiac enlargement itself may accentuate in some degree the left auricular curve (Babey, 1937).

The left (II) oblique position is the only one in which the left branch of the pulmonary artery, hidden in the anterior position behind the greatly dilated pulmonary trunk, can be seen in its course (Schwedel \& Epstein, 1936; Laubry et al., 1939). In 16 of our series it obscured the aortic window by appearing under the aortic arch as a large denser shadow (Fig. 13). The prominence of the right ventricle on the sternal border of the heart is another typical feature in this view.

Radiokymographic studies in A.S.D. (Battro et al., 1937; Levesque et al., 1937; Laubry et al., 1939) have shown normal ventricular pulsation on the left border with ventricular pulsation in its lower part (Battro et al., 1937), an 

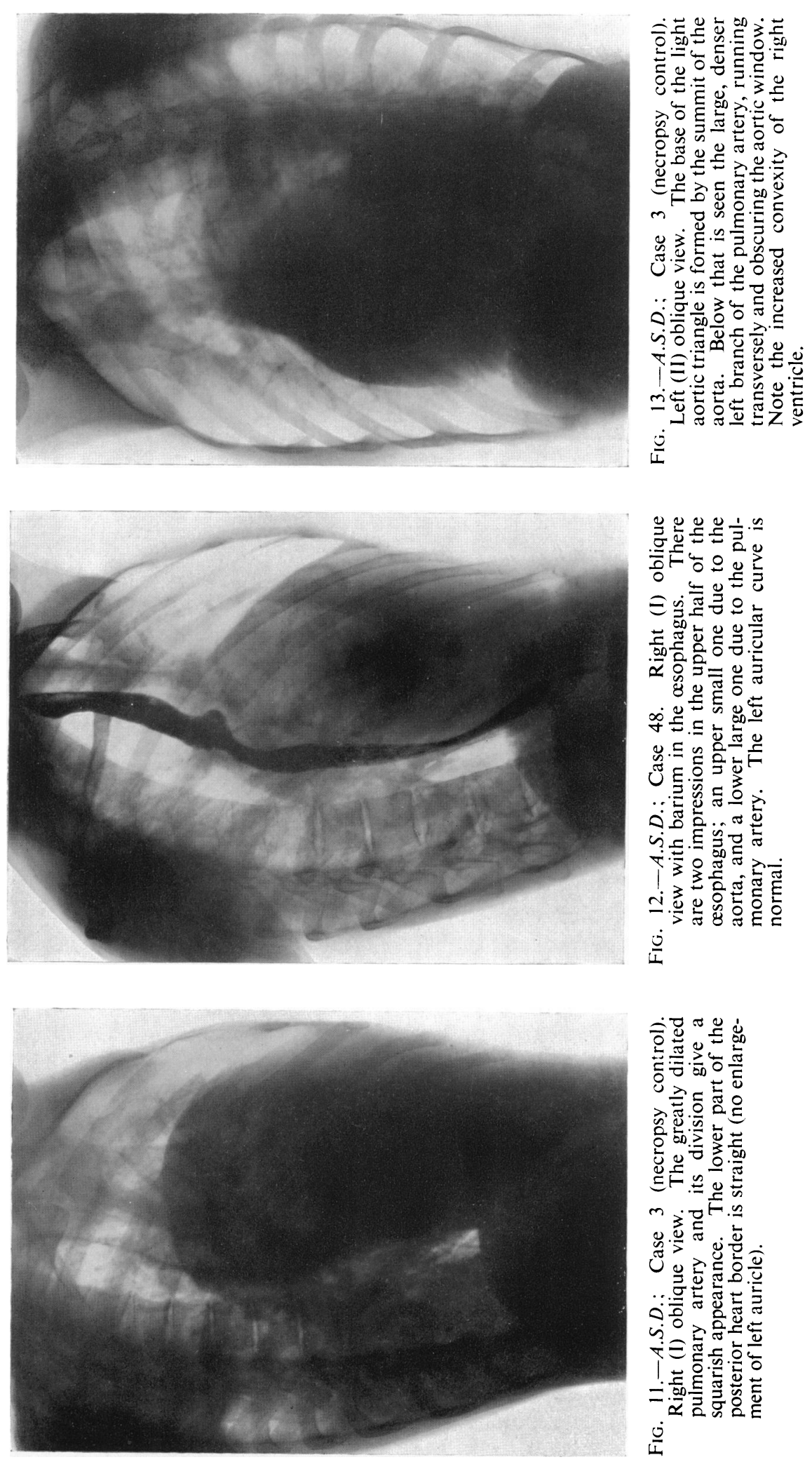
arterial curve in the upper pulmonary artery region, and an arterial curve at the right hilum.

With associated mitral stenosis there is likely to be extreme enlargement of the right auricle, both to X-rays and at necropsy, and this is well shown in Figs. 4, 14, and 16.

In rare cases the pulmonary artery and its branches are not enlarged so that the radiological aspect is quite different (as in Case 9). In the anterior position (Fig. 16) the heart is enormously enlarged to left and right, and of spherical shape suggesting pericardial effusion. The pulmonary artery is not visible though the conus is prominent. "The greatly displaced right border crosses the diaphragm at an obtuse angle. In the right (I) oblique position the left auricle is not particularly prominent. The anatomical peculiarity of this heart with A.S.D. and mitral stenosis (Case 9) was the huge conus almost like a third ventricle (Fig. 4). A transition between this and the typical radiological appearance is to be found in the cases of Roesler (1934) and of Joly (1939), where there was a certain degree of pulmonary artery enlargement but the branches were hidden behind the huge heart. Joly (1939) calls such hearts "pear-shaped" (pyriform), and believes that they occur only in men, and stresses their association with a small aorta; yet in our Case 9 the aorta was normal at necropsy, and Roesler (1934) found this form in a woman.

\section{Electrocardiographic Features}

Atrial septal defect is the only congenital heart lesion in which auricular fibrillation is likely to occur. Among 300 cases of congenital heart diseases Brumlik (1937) found fibrillation only once, and this was in A.S.D. The reason for the association may be gathered from Table VI: in our series it was present in 6 patients (Fig. 17); five of them had mitral stenosis and the sixth, with A.S.D. only, was aged 58 and our oldest patient. If not mitral stenosis implying rheumatism, the predisposing factor for fibrillation appears to be increasing age. We have not found any reports of fibrillation in pure A.S.D. under 50 years of age, and in all the younger cases reported it was associated with mitral stenosis. In Case 10 there was alternating fibrillation and flutter, and in Cases 12 and 44 (both pure A.S.D. cases) there were paroxysmal attacks of nodal tachycardia. Complete heart block has been by Taussig et al. (1938).

Large and high $\mathrm{P}$ waves in one or more leads, described as characteristic for A.S.D. by Leech (1935), were found in 15 records (Figs. 19A; 20A, C). A large bifid $\mathrm{P}$ was seen three times, without mitral stenosis (Fig. 19B). A long P-R interval is rarely mentioned in congenital heart disease, but it has been noticed and ascribed to a secondary myocardial lesion (Mannheimer, 1939), or to a ventricular septal defect (Brumlik, 1937) when there is bundle branch block. In A.S.D. it has not hitherto been remarked though it is apparent in some published records (Cesari, 1935; Brown, 1939). The P-R interval was 0.20 second or more in 19 of our series (Figs. 19A, 20A); it was longest $(0.28 \mathrm{sec}$.) in Case 27 who had also partial right bundle branch block with an enlarged 

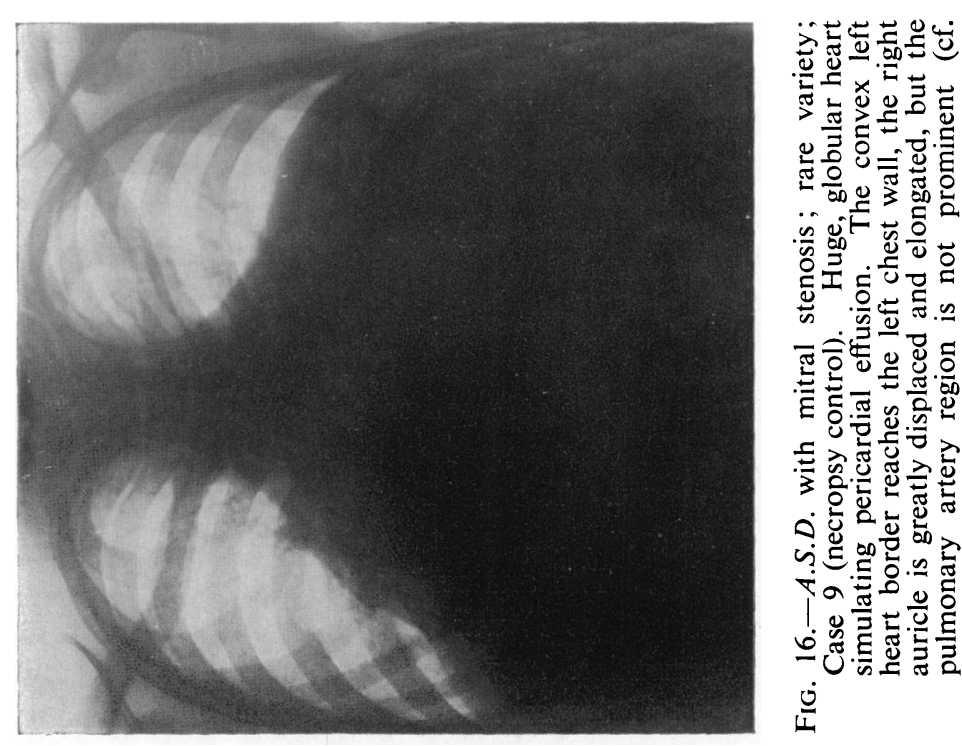

б

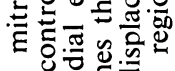

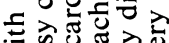

3 응.

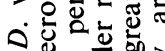

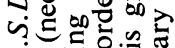

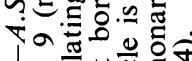

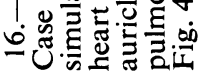

ఏำ
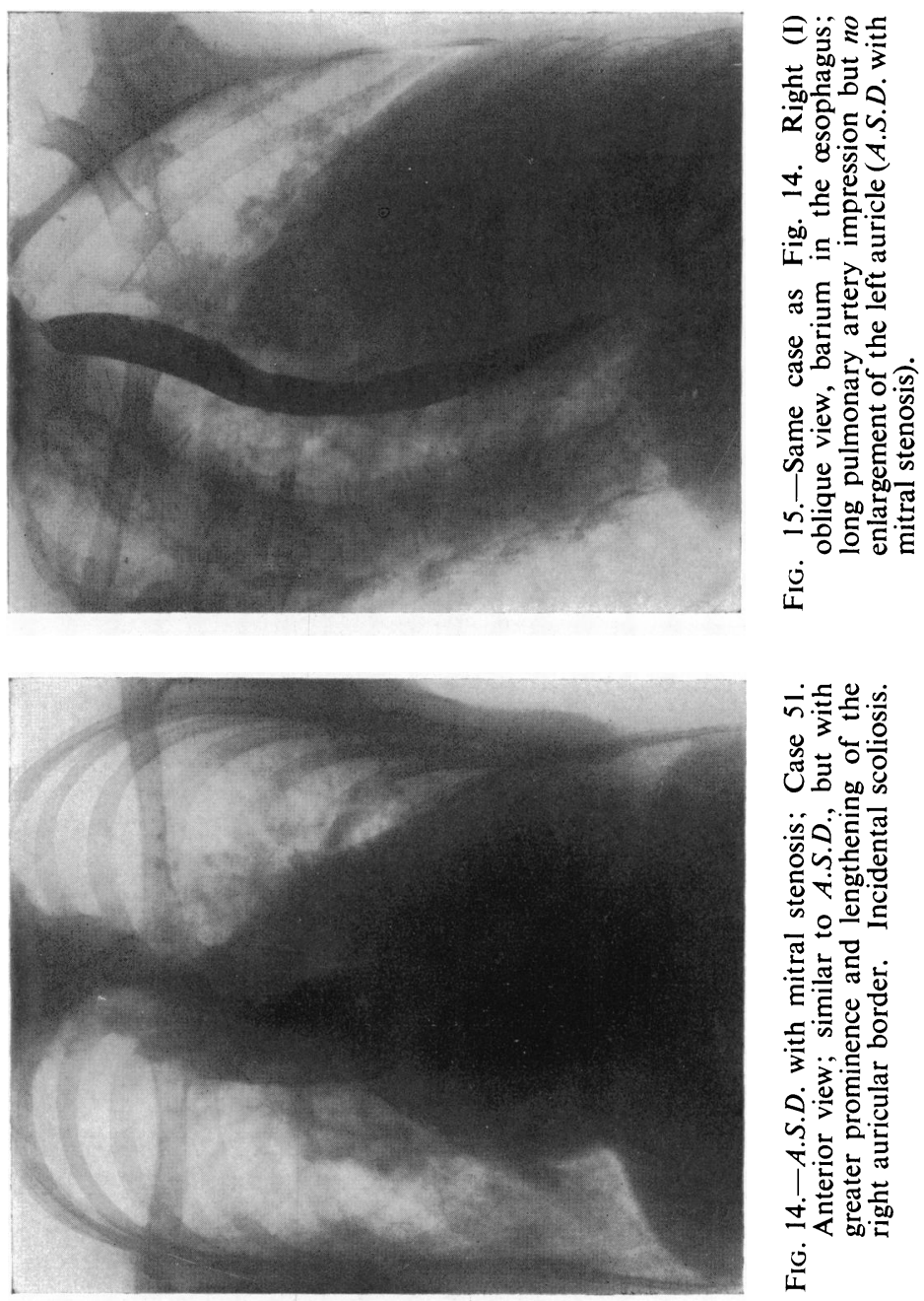
heart but no signs of failure. In Case 28 (Fig. 18) a second record, taken four years after the first and in failure, showed an increase from 0.18 to $0.26 \mathrm{sec}$.

TABLE VI

Electrocardiographic Features

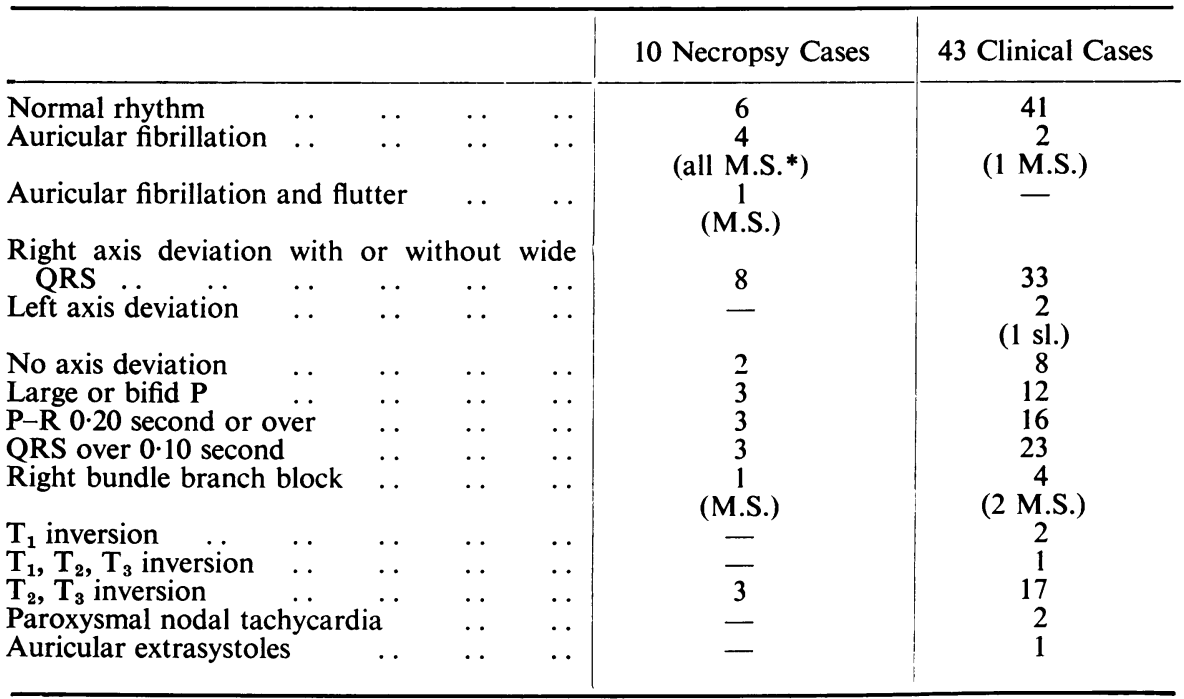

* M.S. $=$ mitral stenosis.

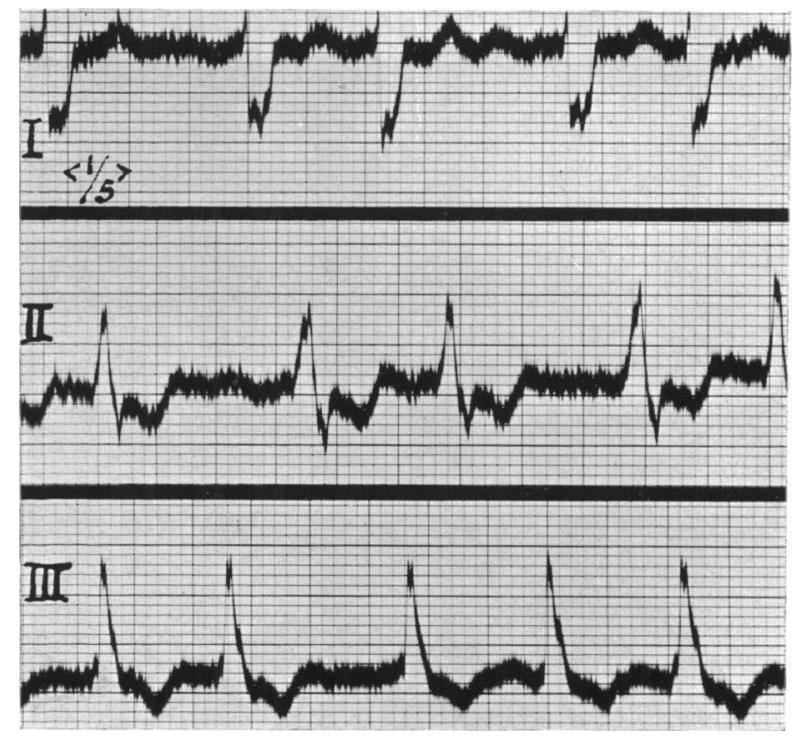

Fig. 17.-A.S.D. with mitral stenosis; Case 51. Auricular fibrillation and right bundle branch block (traditional type). 

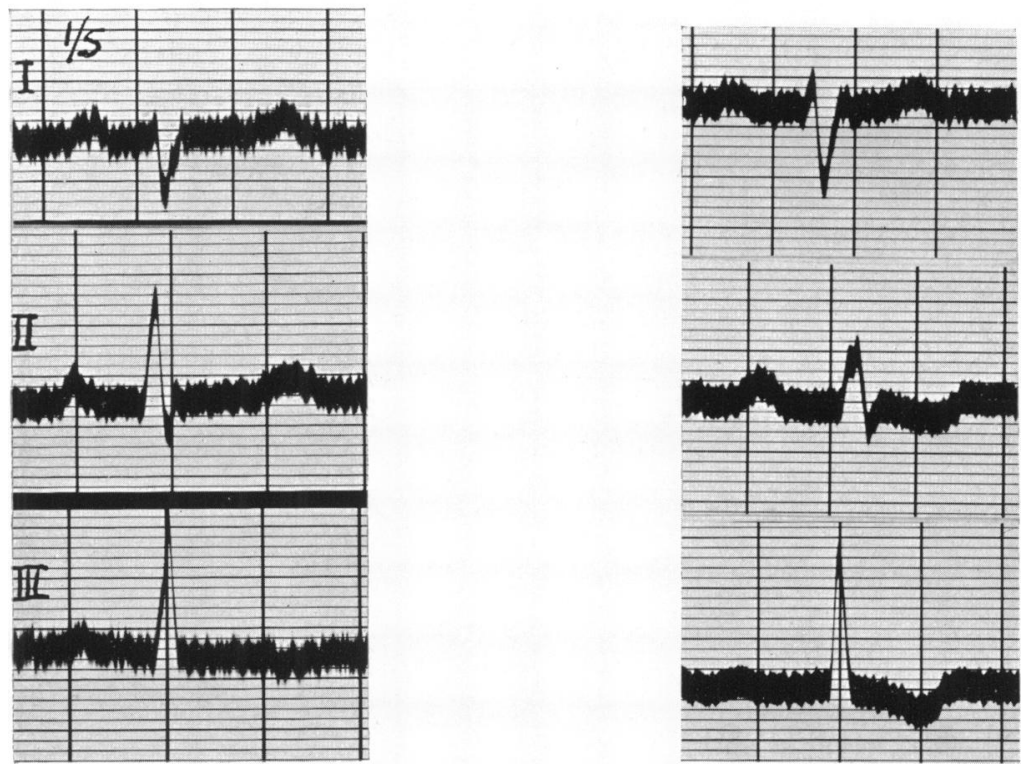

(A) Right axis deviation.

Fig. 18.-A.S.D.; Case 28.

(B) Record taken four years after (A) shows prolonged $P-R$ interval $(0.27 \mathrm{sec}$.), notched and widened $Q R S_{2}\left(0 \cdot 10 \mathrm{sec}\right.$.) and inversion of $T_{2}$ and $T_{3}$.

B
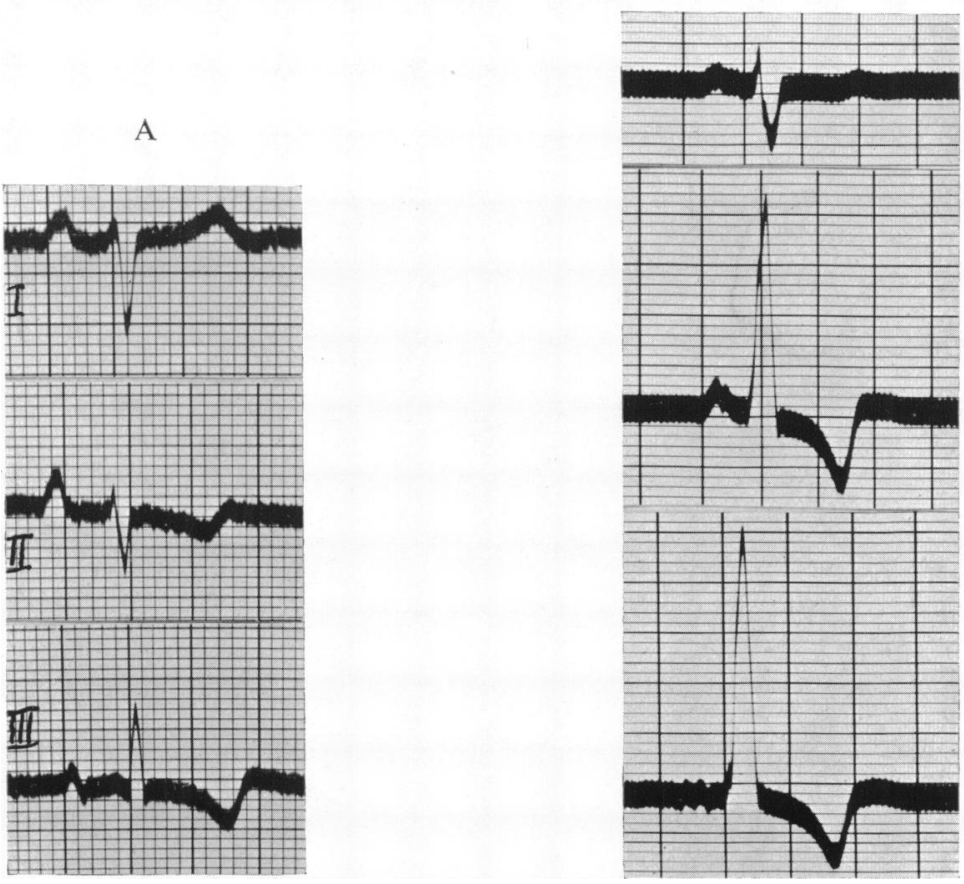

FIG. 19.-A.S.D. with right axis deviation.

(A) Case 1 (necropsy control). Large $P_{2}$, prolonged $P-R$ interval $(0 \cdot 22 \mathrm{sec}$.), inversion of $T_{\text {, and }} T_{3}$.

(B) Case 12. High voltage curve, bifid $P_{2}$ and $P_{3}$, sharp inversion of $T_{2}$ and $T_{3}$. 
The main direction of the waves was (notably in leads I and III) that of right axis deviation, in four fifths of our cases if we include right axis deviation itself and partial right bundle branch block whether of the traditional or of the newer type. It was of high degree (high voltage) in about half of them (Fig. 19B), and of medium or low degree in the other half. The voltage was low in the

A

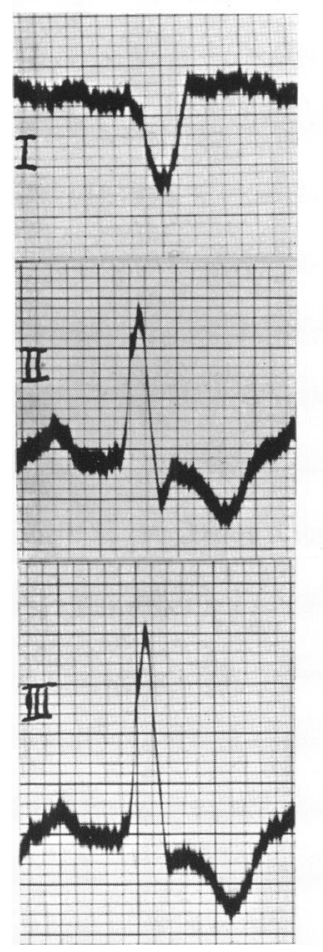

B

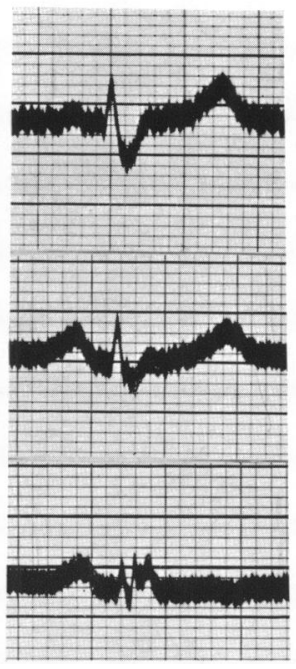

C

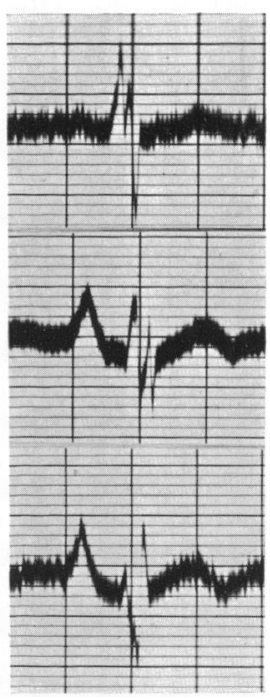

Fig. 20.-A.S.D. with bundle branch block.

(A) Case 5 (necropsy control). P-R interval of 0.22 sec., large $P_{2}$, right bundle branch block of the traditional type.

(B) Case 17. Right bundle branch block of the newer type.

(C) Case 30. Large $\mathbf{P}_{2}$ and $\mathbf{P}_{3}$. Bizarre, notched and widened $(0.12 \mathrm{sec}$.) ventricular complexes.

cases with severe failure (Cases 4, 7, 8, and 9), but it was also low in Cases 17 and 21 with large hearts in the absence of failure.

A widened ventricular complex sometimes suggesting right bundle block was described in A.S.D. (Bedford \& Brown, 1937; Routier \& de Balsac, 1938), and its diagnostic importance was stressed by Routier et al. $(1940, b)$. It was present in 26 of our series. Every transition from a prolonged intraventricular conduction or simple notching to right bundle branch block, sometimes of the old (Fig. 20A), sometimes of the newer type (Fig. 20B) could be found; incomplete bundle block was more frequent ( 21 cases) than complete ( 5 cases). This wide and notched QRS was found only twice below the age of 30 and then with moderate cardiac enlargement. This fact with its appearance in the later 
record of Case 28 (Fig. 18B) also indicates, as Routier et al. (1940) maintain, the progressive effect of the lesion on the myocardium accompanied by enlargement: the bundle block appearance is not part of the congenital lesion but a sequel of it. It was nearly always accompanied by an inversion of the $T$ wave in lead II or III, or in both, though in nine cases such inversion of $\mathrm{T}$ was present with normal ventricular complexes (Fig. 19A). It is related to right ventricular stress (Barnes \& Whitten, 1929; Brumlik, 1937) and is another feature of the second record in Fig. 18B.

\section{Cardiac Enlargement and Failure}

The onset of failure was never before the third decade of life, except in Cases 2 and 4 where it appeared at 7 and 28 years and was due to complicating broncho-pneumonia and bacterial endocarditis respectively. In our clinical series, failure appeared in two between 30 and 40, and in four between 50 and 60 .

The failure is typically right-sided. After a period of dyspnœa on exertion for 10-20 years, often surprisingly slight, the liver enlarges and sometimes pulsates from tricuspid incompetence. Cyanosis begins to appear on slight effort. This stage may last for a few years before œdema and ascites supervene.

Pulmonary congestion and hydrothorax are rare, as always in pure rightsided failure (see Radiological Features), and are referable to associated auricular fibrillation rather than to the defect itself (Cases 7, 8, 9, 34, and 51). Pulmonary infarction may be a terminal event; but if pulmonary infarction occurs early, it depends upon pulmonary arteriosclerosis, as it did in cases 37 and 42, both with hæmoptysis at the age of 22 and 26, and in the two necropsy Cases 1 and 5.

The mechanism of right-sided heart failure in atrial septal defect is explained by the pressure difference in the two atria. The higher pressure in the left atrium which normally causes the closure of the foramen ovale is responsible for the shunt from left to right. The increased blood volume passing through the right cavities and the pulmonary arteries is the cause of their enlargement, and conversely of the smallness of the aorta and the left ventricle. When after decades of adaptation to the increased circulatory load the right ventricle fails, the raised pressure in the right auricle gives rise to the known signs of right ventricular failure and reverses the flow and produces cyanosis (cyanose tardive). It would be logical to suppose that the precocity of failure should depend upon the blood volume passing through the defect, according to the dimension of the defect and to the degree of left auricular pressure. But it is difficult to establish a strict relation between the dimension of the defect and the size of the heart chambers (see under Pathology); on the other hand, the increased left auricular pressure from co-existent mitral stenosis produced the greatest distension of the heart chambers.

This view of the circulatory mechanism admitted since Mayne (1848), Rokitansky (1875), and Griffith (1906), has recently been rejected by Laubry and Lenégre (1939), Laubry et al. (1939), Marchal et al. (1939), Routier (1939), and Routier and Brumlik (1940). The French authors regard A.S.D. as a silent symptomless lesion, a minor element in a complex congenital heart lesion 
characterized by huge right cavities and a dilated pulmonary artery, and a hypoplasic aorta and left ventricle. The A.S.D. itself would not account for the secondary alterations leading to failure, unless it were associated with mitral stenosis. But the cases of Laubry and Lenégre (1939) and of Marchal et al. (1939) - regarded as supporting their opinion-are admittedly examples of widely patent foramen ovale (not true A.S.D.), and this explains the absence of typical heart responses. Nor are the three cases of chronic pulmonary disease published by Routier and Brumlik (1940) convincing, for it is well known that fibroid lung may produce dilatation of the pulmonary artery and a heart very like that found in A.S.D. Another argument advanced by Joly (1939) and Olmer et al. (1939) is based on the variety of the heart changes (if any) in A.S.D., sometimes enlargement of the pulmonary artery, but in other cases enlargement of the conus, or even a normal heart. But as shown in our series, enlargement of the pulmonary artery is almost a constant feature in real A.S.D., as it was in all the series yet published (Rokitansky, 1875; Roesler, 1934; McGinn \& White, 1933). This would not exclude the possibility that the conus may enlarge more than the pulmonary artery as in Roesler's case (1934), or that in exceptional cases a huge conus and a normal pulmonary artery may be found (our Case 9). Even in simple mitral stenosis, it is sometimes the conus and sometimes the pulmonary artery that enlarges the more. The different behaviour of the pulmonary artery in these circumstances is not only referable to the mechanical effect created by the lesion, but to a congenital hypoplasia of the vessel wall which is fairly common (Clarke, Coombs, Hadfield, \& Todd, 1929; Costa, 1929; Brenner, 1935). In the second case of Olmer et al. (1939), in which A.S.D. was found in a woman aged 27 who died of intercurrent disease with a heart that was otherwise normal at necropsy, no measurements of the defect are given and the accompanying figure suggests that it was very small.

Against these later views are many facts to show it is the A.S.D. that produces the pathological alterations and eventually the heart failure:

(1) Since A.S.D. gives somewhat similar anatomical alterations whether alone or combined with mitral stenosis, the complicating mitral stenosis cannot be the only and sufficient cause of such alterations.

(2) A normal aorta with a large pulmonary artery, found in 4 of our 10 necropsies, is against a congenital inequality of the two vessels. The hypoplasia of the aorta in the 6 remaining necropsy cases is ascribed to the diminished blood volume reaching the left ventricle: a similar aortic hypoplasia is seen when mitral stenosis develops in early life. An unequal division of the bulbus arteriosus, as described by Assmann (1928) and Oppenheimer (1933), and as applied by the French authors, does occasionally produce a pathological and radiological picture similar to that of A.S.D. (see Differential Diagnosis).

(3) Freedom from symptoms and good capacity for exertion up to the twenties or thirties indicates late and progressive enlargement resulting from the $A . S . D$.

(4) That dilatation of the right ventricle is a sequential progression and not part of the congenital lesion is suggested by the changes in the electrocardiogram already described. 


\section{Diagnosis}

The diagnosis of atrial septal defect rests mainly on its radiological features. The great, even aneurysmal, dilatation of the pulmonary artery with its grossly dilated and often pulsating right branch, standing out against a clear lung field, strikes the eye definitively in the anterior view. The heart is enlarged as a whole and especially to the left. The enlarged pulmonary artery is well seen in the right (I) oblique view, but the visualized œsophagus shows no particular enlargement of the left auricle.

The clinical signs are of limited value and are essentially those of enlargement of the right ventricle and dilatation of the pulmonary artery without obvious cause. Thus the apex beat is forcible and displaced to the left, but the blood pressure is normal or low. The signs of dilatation of the pulmonary artery may be unobtrusive, or may be those of aneurysm such as palpable pulsation, systolic thrill, and diastolic shock. A systolic murmur (sometimes also a diastolic) and an accentuated second sound are usually heard at the pulmonary area. Cyanosis from birth is exceptional, and it is absent or slight unless terminal heart failure is present; clubbing is uncommon. Widespread pulmonary congestion is noticeably absent, and there is greater capacity for exertion than would be expected from the clinical and even more from the radiological pointers.

The electrocardiogram may help, for right axis deviation with normal rhythm is the rule, with QRS often notched and widened and approximating to the right bundle block type, yet with $T$ inverted independently in leads II and III. Large $\mathrm{P}$ waves and a prolonged $\mathrm{P}-\mathrm{R}$ interval are not infrequent.

A.S.D. associated with mitral stenosis produces a very similar combination of signs, but in addition there is the auscultatory monomark of mitral stenosis, and auricular fibrillation is common. The left auricle is not enlarged; or if it is, then not disproportionately to the general enlargement. Great prominence of the right auricle is of major importance in the diagnosis of this combination. In brief, the radiological aspects of A.S.D. with or without mitral stenosis are similar, though the former may perhaps show more enlargement to the right (R.A.) and the clinical and electrocardiographic findings of mitral stenosis.

Differential diagnosis is concerned with any heart condition, acquired or congenital, in which great enlargement of the pulmonary artery and its branches is found. This applies to mitral stenosis, patent ductus arteriosus, pulmonary or conus stenosis with normal ventricular septum, ventricular septal defect alone or with dextroposed aorta (Eisenmenger's disease), pulmonary heart disease, pulmonary artery disease, and primary dilatation of the pulmonary artery with right ventricular hypertrophy (pulmonary hypertension). In attempting differential diagnosis it should always be remembered that A.S.D. is often combined with other congenital lesions.

(a) Mitral stenosis. Fair capacity for exertion in mitral stenosis with an enlarged heart is unusual, and, of course, auricular fibrillation is common. By $\mathrm{X}$-rays, the heart presents a straight left border because the conus as well as the pulmonary artery are both projecting. The left auricle invariably enlarges and displaces the barium-filled œsophagus in the right oblique view. The lung 
fields are clouded and merge with the hila because there is general pulmonary congestion. Difficulties can arise if in mitral stenosis there is an exceptionally large pulmonary artery-perhaps with relative pulmonary incompetence (Graham Steell)—but then the enlarged left auricle and the diffuse pulmonary congestion will exclude A.S.D., whether with or without mitral stenosis.

(b) Patent ductus arteriosus. Only when the typical murmur is absent and the pulmonary artery and branches are unusually large will confusion arise. Cyanosis is absent in both lesions and a pulmonary diastolic murmur is occasionally heard in both. A normal or almost normal electrocardiogram favours patent ductus arteriosus (Drawe et al., 1937) and the cardiac enlargement is expected to be slighter than in A.S.D.

(c) In both pulmonary or conus (right ventricle) stenosis with a normal ventricular septum the pulmonary second sound is absent and the branches of the pulmonary artery are not enlarged though the stem of the pulmonary artery may be distended.

(d) In isolated ventricular septal defect (Roger's disease), gross enlargement of the pulmonary artery is most exceptional, and in Eisenmenger's disease the dextroposition of the aorta may be distinctive.

(e) In pulmonary heart disease the enlargement of the pulmonary artery (and the conus) seldom reaches the degree so common in A.S.D., and the causal emphysema, chronic bronchitis, or fibroid lung is obvious from the history and the signs.

(f) Pulmonary artery disease is far from common; it may be a primary atheroma or more likely syphilis of the trunk and main branches. There is also the obliterative endarteritis of the finer branches alone or as part of a chronic lung disease. The diagnosis can be very difficult, yet the long history of pulmonary symptoms and the cyanosis or the positive Wassermann reaction may decide it.

(g) Most difficult of all to distinguish from A.S.D. are the cases of primary dilatation of the pulmonary artery and its branches, without much pathological alteration excepting right ventricular hypertrophy. This group has been attributed to unequal division of the common trunk (Assmann, 1928), idiopathic dilatation of the pulmonary artery (Oppenheimer, 1933), congenital disproportion between aorta and pulmonary artery (Routier \& Brumlik, 1940), pulmonary hypertension (Lian, 1940; East, 1940; Armstrong, 1940), and to idiopathic right ventricular hypertrophy (De Navasquez, Forbes, \& Holling, 1940). Lian (1940) published 21 clinical cases that he believed were of this nature, but they were a mixed group and no necropsy evidence is afforded; in fact necropsies on this condition are rarely though increasingly reported. (Oppenheimer, 2 cases; East, 3 cases; De Navasquez et al., 3 cases). It must be admitted that the whole picture in advanced cases is identical and differential diagnosis during life may be impossible. But A.S.D. is so common and "pulmonary hypertension" so rare, that pathological statistics (probability) should weight in any doubtful case of gross enlargement of the pulmonary artery and its branches. 


\section{SUMMARY}

(1) A patent foramen ovale (patent to probe or even to pencil), found in 20-30 per cent of all necropsies, is an anatomical variation of a normal condition; it is clinically silent except that when distended by increased right auricular pressure ("widely patent") it can give rise to terminal cyanosis and paradoxical embolism. In contrast, atrial septal defect (A.S.D.) is a real congenital malformation due to a defective union or malformation of the three embryonic septa forming the definitive atrial septum. It occurs $(a)$ as a single lesion and constitutes 7-25 per cent of all congenital heart lesions; $(b)$ as an associated lesion with any other congenital heart lesion; $(c)$ combined with mitral stenosis, and then probably with auricular fibrillation.

(2) A diagnosis of A.S.D. was made in 53 patients, 10 with necropsy control and 43 without. An association with mitral stenosis was present in 4 of the necropsy cases-one had also adhesive pericarditis-and in 4 of the clinical cases, and with patent ductus arteriosus and ventricular septum defect in 1 necropsy case. The lesion may be found at any age and the prevalence of females was striking (4:1). The age of death was mostly between 30 and 50 . The cause of death was congestive heart failure in three, pulmonary infarction in two, embolism (one paradoxical) in two, subacute bacterial endocarditis in one, broncho-pneumonia in one, and operation in one.

(3) The pathological findings in the 10 necropsy cases were:

(a) A large heart consisting mainly of right ventricle, conus, and right auricle, with a disproportion between right and left cavities of about 3:1 in bulk, or even more in cases of associated mitral stenosis.

(b) Gross dilatation of the pulmonary artery and its branches, except in one case where there was a big conus with a normal pulmonary artery. Severe arteriosclerosis (with thrombosis of the pulmonary artery and branches) was found only once, and in lesser degree three times; the remainder showed simple thickening only.

(c) The atrial septum was almost absent in one; the defect involved the lower part of the septum and there was an imperfect formation of the tricuspid valve (persistent ostium primum) in another; and its site was the enlarged fossa ovalis or the upper part of the septum in the remainder. The dimension of the defect varied from 1 by $0.8 \mathrm{~cm}$. to 7 by $4 \mathrm{~cm}$. There was no strict relation between the dimension of the defect and the degree of pathological adjustment.

(4) Auditory signs in A.S.D. are lacking, for the lesion itself produces no murmur. Any murmurs heard are due to dilatation of the right ventricle and the conus, and relative stenosis of the less distensible pulmonary ring. A systolic murmur in the pulmonary area was found in 32 and was accompanied by a systolic thrill in 13 cases. An accentuated pulmonary second sound in 31 , was followed by a diastolic murmur in 10: no murmurs were recorded in 8 cases. A forcible and displaced apex-beat without other cause and due to the large right ventricle proved to be a most suggestive sign ( 32 cases). Common clinical features in our 53 cases were fair capacity for exertion even with an enlarged heart and signs of failure ( 27 cases), slight cyanosis on effort or late cyanosis 
(31 cases). Underdevelopment, though occasionally seen (8 cases), was far less frequent than in other published statistics.

(5) The radiological features in 51 cases indicated its paramount importance in diagnosis. General enlargement was present in 40, chiefly to the left in 30 . The prominence of the left border proved to be due, however, to the enlarged right ventricle (see left oblique view) which displaced the left ventricle backwards. Great projection of the right auricle points to coexisting mitral stenosis. The bulging of the pulmonary stem and conus with the enlarged, dense right hilum shadow (right branch of the pulmonary artery) gives the heart its striking appearance in the anterior view. Excessive pulsation of the hilum was noticed in 31 instances; but a real " hilar dance" could be seen in only 5 , and then there was not always pulmonary incompetence. Lack of pulsation with increased density was diagnostic of local thrombosis in one necropsy case. The aorta was small or invisible in about half the cases. In the right (I) oblique view the enlargement of the pulmonary stem and conus became even more evident, and a pulmonary impression on the œsophagus was observed in 18 of our cases. In the left (II) oblique view, the enlarged left pulmonary branch obscured the aortic window and the right ventricle was unduly convex. Negative radiological signs of importance were the absence of the left auricular curve in the right oblique view, and the absence of lung congestion. In the six cases where the left auricular curve was prominent it was proportionate to the general cardiac enlargement. Pulmonary congestion was found in only three cases having severe failure, and hydrothorax in only two-both in terminal conditions.

(6) The electrocardiogram often helped in diagnosis. Normal rhythm was the rule (in 47), and when auricular fibrillation was present it was not due to the lesion itself but either to rheumatism (mitral stenosis) or to age changes. Right axis deviation was very frequent (in 41), if we include partial right bundle branch block (26); complete right bundle branch block of the older or newer type was found in 5. $T_{2}$ and $T_{3}$ were inverted, independently of the bundle branch block character of the ventricular complex (in 9). A prolonged $P-R$ interval of 0.20 second or over, and large or bifid $P$ waves were not infrequent.

(7) Failure appeared usually between the ages of 30 and 50, and was typically right ventricular. Late cyanosis and liver enlargement were its main features; dyspnœa was moderate and pulmonary congestion was rare unless in the terminal stage when œdema and ascites might supervene. Pulmonary infarction early in the course was rare and then based upon pulmonary arteriosclerosis. Subacute bacterial endocarditis as a complication was exceptional (one necropsy case). The mechanism of failure is explained by the increased blood volume that the right ventricle has to propel, for the left atrium with its higher pressure partly diverts through the defect blood from the left cavities. We cannot accept the hypothesis recently advanced by French authors that the disproportion between right and left cavities and between pulmonary artery and aorta respectively is due to a congenital malformation unless $A . S . D$. is associated with mitral stenosis. The similarity of the pathological findings in A.S.D. with or without mitral stenosis, the progressive dilatation of the right ventricle, and the often normal aorta make us reject this view. 
I (8) JDifferential diagnosis is concerned with all congenital or acquired heart conditions in which there is a dilatation of the pulmonary artery and its branches, and these are enumerated. Pulmonary artery disease and primary dilatation of the pulmonary artery with right ventricular hypertrophy, so-called pulmonary hypertension, can produce a similar radiological and pathological picture. But these are exceptional conditions, while atrial septal defect is a far more likely cause of gross dilatation of the pulmonary artery and its branches.

We wish to thank Dr. Doris Baker, Dr. Izod Bennett, Dr. F. G. Chandler, Professor R. V. Christie, Dr. Horace Evans, Dr. K. H. Tallerman, Dr. Cecil Wall, and Professor K. D. Wilkinson (Case 2), for their kindness in allowing us to use cases under their care. Dr. William Evans kindly gave us his complete records on Case 4. The necropsy report on Case 8 is given by courtesy of Professor H. M. Turnbull and Dr. W. W. Woods of the Pathological Institute of the London Hospital, and that of Case 10 by Dr. T. Skene Keith of the National Heart Hospital. Dr. John Grimshaw has been good enough to help us with the text.

\section{REFERENCES}

Abbott, M. E. (1915). Bull. Internat. Assoc. Med. Mus., 5, 129.

- (1937). Congenital Heart Disease in Nelson's New Loose Leaf Medicine, 18th ed., vol. IV, 207.

Armstrong, T. G. (1940). Brit. Heart J., 2, 201.

Ash, R., Wolman, I., and Bromer, R. (1939). Amer. J. Dis. Child., 58, 8.

Assmann, H. (1928). Die klinische Röntgendiagnostik der inneren Erkrankungen, 4th ed., Leipzig.

Babey, A. (1937). Amer. Heart J., 13, 228.

Bard, L., and Curtillet, J. (1889). Rev. Médecine, 9, 993.

Barnard, W. G. (1930). Quart. J. Med., 23, 305.

Barnes, A. R., and Whitten, M. B. (1929). Amer. Heart J., 5, 14.

Battro, A., and De La Serna, A. (1937). Rev. argent. Cardiol., 3, 427.

Bedford, D. E., and Brown, J. W. (1937). Brit. Encycl. Med. Pract., vol. VI.

Brenner, O. (1935). Arch. intern. Med., 56, 211.

Brown, J. W. (1939). Congenital Heart Disease, London.

Brumlik, J. (1937). Ann. Soc. Tchécosl. Cardiol., 5, 109.

Cesari, A. M. (1935). Cuore e Circolaz., 19, 213.

Chase, R. E. (1938). J. Techn. Methods, 18, 90.

Clarke, R. C., Coombs, C. F., Hadfield, G., and Todd, A. T. (1929). Quart. J. Med., $21,51$.

Corvisart (1841). Traité des maladies du cour, vol. II, 680, Paris.

Cossio, P., and Arana, R. S. (1937). Bull. Acad. Med. Paris, 117, 212.

—- Arana, R. S., Berconsky, I., and Kreutzer, R. (1938). Sem. méd., B. Aires, 2, 364.

- and Berconsky, I. (1936). Rev. argent. Cardiol., 3, 360.

Costa, A. (1928). Arch. Patol. clin. Med., 7, 329. (1931). Cuore e Circolaz., 15, 263.

Cruveilhier, J. (1852). Traité d'anatomie pathologique générale, vol. II, Paris.

De Navasquez, S., Forbes, J. R., and Holling, H. E. (1940). Brit. Heart J., 2, 177.

Drawe, C. E., Hafkesbring, E. M., and Ashman, R. (1937). Amer. J. Dis. Child., 53, 1470.

Dressler, W., and Roesler, H. (1930). Z. klin. Med., 112, 421.

Duff, P. A. (1938). J. Techn. Methods, 18, 106.

East, T. (1940). Brit. Heart J., 2, 189.

Feldman, W. M., and Snook, S. G. (1938). Brit. J. Child. Dis., 35, 183.

Firket, C. (1880). Ann. Soc. méd. chir. Liége, 19, 188 (quoted by Roesler, 1934).

Gibson, S., and Clifton, W. M. (1938). Amer. J. Dis. Child., 55, 761.

- and Roos, A. (1935). Ibid., 50, 1465.

Griffith, T. W. (1903). Med. Chronicle, Manchester., 37, 385. (1906). Lancet, 2, 973.

Heim de Balsac, R. (1939). Arch. Mal. Cour, 32, 199.

Hirschboeck, F. J. (1935). Amer. J. med. Sci., 189, 236.

Ingham, D. W. (1938). J. Techn. Methods, 18, 131.

Jacobius, H. L., and Moore, R. A. (1938). J. Techn. Methods, 18, 133.

Joly, F. (1939). Paris méd., 1, 441.

(1939). Arch. Mal. Creur, 32, 611.

Jones, R. (1936). Brit. med. J., 2, 225.

Joules, H. (1934). Lancet, 2, 1338

Koritschoner, R. (1936). J. Amer. med. Ass., 106, 1269.

Laubry, C., Cottenot, P., Routier, D., and Heim de Balsac, R. (1939). Radiologie Clinique du cour et des gros vaisseaux, Paris.

Laubry, C., and Lenègre, J. (1939). Arch. Mal. Cour, 32, 197. 
Laubry, C., and Pezzi, C. (1921). Traité des maladies congénitales du cour, Paris.

Leech, C. B. (1935). J. Pediat., 7, 802.

Levesque, J., Heim de Balsac, R., and Guichard, H. (1937). Ann. de Méd., 42, 229.

Lian, C. (1940). Arch. Mal. Cour, 33, 67.

Löfgren, L. (1937). Finska Läksällsk. Handl., 80, 919.

Louis, P. C. A. (1826). Mémoires ou recherches anatomo-pathologiques, Paris.

Lutembacher, R. (1916). Arch. Mal. Cour, 9, 237.

- (1936). Ibid., 29, 229.

Mannheimer, E. (1939). Acta paediatr. Stockh., 24, 128.

Marchal, J., Ortholan, J., and Breton, P. (1939). Arch. Mal. Crur, 32, 189.

Martineau (1865). Bull. Soc. Anat. Paris, 10, 310.

Mayne, A. B. (1848). Dublin Quart. J. Med. Sci., 5, 46.

McGinn, S., and White, P. D. (1933). Amer. Heart J., 9, 1. (1936). New Engl. J. Med., 214, 763.

McLeod, N. (1936). J. Techn. Methods, 15, 131.

O'Farrell, P. T. (1938). Irish J. Med. Sci., 6, 597.

Olmer, D., Jouve, A., and Claustre, P. (1939). Marseille méd., 1, 487.

Oppenheimer, B. S. (1933). Trans. Assoc. Amer. Phys., 48, 290.

Parkinson, J., and Bedford, D. E. (1931). Lancet, 2, 337.

Peacock, T. B. (1860). Trans. Path. Soc. London, 11, 68.

Pezzi, C. (1925). Atti Soc. Lomb. Sci. Med. biol., 14, 52. (1932). Contributions to Medical Sciences in Honor of Dr. E. Libman. International Press, New York, 3, 931.

_ (1937). Sur le diagnostic de la communication interauriculaire (Prof. Libensky's Jubilee Book, p. 52, Prague).

Robb, G. P., and Steinberg, I. (1939). Amer. J. Roentgen., 41, 1; $42,14$.

Roesler, H. (1934). Arch. intern. Med., 54, 339.

- (1937). Clinical Roentgenology of the Cardiovascular System, London.

- (1939). Atlas of Cardioroentgenology, Springfield, Ill., U.S.A.

Rokitansky, C. (1875). Die Defecte der Scheidewände des Herzens, Wien.

Routier, D. (1939). Arch. Mal. Cour, 32, 207.

and Heim de Balsac, R. (1938). Bull. Soc. Belge Cardiol., 5, 41.

—_ and Brumlik, J. (1940, a). Arch. Mal. Cour, 33, 184.

- Brumlik, J., and Malinsky, A. (1940, b). Ibid., 33, 40.

Sailer, S. (1936). Amer. J. Path., 12, 259.

Schwedel, J. B., and Epstein, B. S. (1936). Amer. Heart J., 11, 292.

Tarnower, H., and Woodruff, I. O. (1936). Ibid., 12, 358.

Taussig, H. B. (1938). Ibid., 16, 728.

- Harvey, A. McG., and Follis, R. H. (1938). Bull. Johns Hopkins Hosp., 63, 61.

Thompson, T., and Evans, W. (1930). Quart. J. Med., 23, 135.

Tylecote, F. E. (1903): Lancet, 2, 821.

Van Ruyven, R. L. J. (1936). Bull.' Soc. Belg. Card., 3, 98.

\section{APPENDIX OF CASE NOTES}

The following abbreviations have been used:

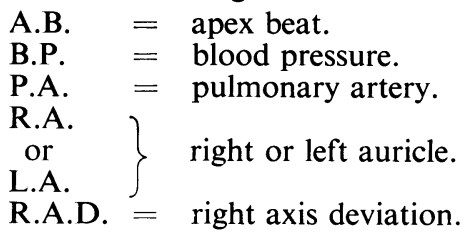

$\left.\begin{array}{l}\text { R.V. } \\ \text { or } \\ \text { L.V. }\end{array}\right\}$ right or left ventricle.
W.R. $=$ Wassermann reaction.
a.a.l. = anterior axillary line.
l.o.p. $=$ left oblique position.
r.o.p. $=$ right oblique position.

Case 1.-H. H., male, aged 44.

History.-Served in Navy 1910-1919, always fit; worked as driver until 1933. Never blue as a child; blueness first noticed about 1919, later worse and associated with dyspnœa on effort. Occasional hæmoptysis, accompanied by severe pain in right side of chest in 1929 and 1937.

Examination (January 1938).--Intense cyanosis, with clubbing; great dyspnœa. Pulse 80, regular. B.P. 110/85. Heart; A.B. fifth left space, a.a.l. Expansile and forcible pulsation in second and third left space near sternum with diastolic shock. Pulmonary second sound very loud, followed by a low pitched diastolic murmur along left sternal border to apex (murmur heard by D.E.B. in 1933 and interpreted as 
pulmonary incompetence). Lungs: crepitations at both bases. Liver: slightly enlarged. Blood count: red cells, $6.5 \mathrm{~m}$; hæm. 140 per cent. Circulatory time (decholin) varied from 15 to $20 \mathrm{sec}$.

Radioscopy.-Heart moderately enlarged to left. Aneurysmal dilatation of pulmonary arc and right P.A. with scarcely any visible pulsation (Fig. 9). Deep P.A. impression on œsophagus, L.A. normal (r.o.p., barium in œsophagus). R.V. prominent, intensely pulsating (1.o.p.).

Electrocardiogram (Fig. 19A).-Normal rhythm; R.A.D.; P-R prolonged (0.22 sec.); large $P_{2} ; T_{2}$ and $T_{3}$ inverted.

Course.-Worked until May, 1938, as lift attendant, when sudden severe pain in left side of chest, and cough with pink frothy expectoration. Re-admitted as acute pulmonary odema; signs of consolidation in left lower lobe. Died four days later. The clinical diagnosis was auricular septum defect with pulmonary incompetence and aneurysmal dilatation of pulmonary artery and branches with old and terminal pulmonary thrombosis.

Necropsy (May, 1938).-On opening the pericardium, P.A. enormously dilated; diameter of trunk $5.5 \mathrm{~cm}$.; that of the aorta, $2.5 \mathrm{~cm}$. at base. Most of left heart contour formed by R.V. The right and left branches of the P.A. greatly dilated $(3.5 \mathrm{~cm}$. in diameter), and walls hardened and thickened. Right and left pulmonary branches largely filled with laminated and organized also recent clots; two-thirds of the lumen of the right branch, half the lumen of the left branch obliterated (Fig. 2).

On opening the heart, R.V. much dilated and hypertrophied, its wall being 1.3 to $1.7 \mathrm{~cm}$. thick. The septal cusp of the tricuspid valve imperfect and rudimentary. R.A. dilated.

Foramen ovale closed, but admits a probe. Fossa ovalis, $2 \mathrm{~cm}$. in diameter, bulges into L.A. Below $(1.5 \mathrm{~cm}$.) the lower border of the fossa ovalis is an oval aperture of 2 by $3.5 \mathrm{~cm}$. The upper border of this aperture is formed by a double fold of the septum, the lower border being formed by the tricuspid and mitral valves.

Considerable atheroma and patchy calcification of P.A. and main branches. Pulmonary cusps normal, but valve incompetent from dilatation of artery. L.V., L.A., mitral and aortic valves are normal.

Final Diagnosis.-Defect of interauricular septum (lower part), hypertrophy and dilatation of R.V., aneurysmal dilatation of P.A. and main branches with organized thrombus of branches. Terminal bronchopneumonia.

Case 2.-H. J., female, aged 7 years.

History.-Attacks of cyanosis and dyspnœa on exercise. Lately troubled with cough, fever, and sweating.

Examination.-Cyanosis and dyspnoa on the slightest exertion. Wasting and weakness. Heart; A.B. visible in sixth left space, a.a.l.; forcible. Palpable thrill over whole præcordial area. Loud rumbling murmur throughout the whole cardiac cycle, maximum sixth space beyond nipple line, but heard over entire chest. Lungs: crepitations and rhonchi, general signs of consolidation over left chest. Liver enlarged.

Radioscopy (Fig. 8). Greatly enlarged heart joining in its lower half the left chest wall. Pulmonary arc and conus very prominent, right pulmonary branch enlarged. Aortic knob invisible.

Electrocardiogram.-Rate 125, normal rhythm; R.A.D.

Course.-Died a week after admission. The clinical diagnosis was pericarditis and congenital heart disease.

Necropsy.-Pericardium contains small amount of clear fluid. Heart enlarged to left chest wall. R.A. and R.V. form two thirds of heart volume. Large patent foramen ovale (Fig. 3). P.A. three times normal size. Small aorta. CEdema and congestion of lungs. Bronchopneumonia. Liver congested.

Case 3.-N. K., female, aged 44. Married, 3 children.

History.-Growing pains, but not acute rheumatism or chorea. At 39 told she had valvular heart disease; then no complaints. Two years sternal pain across upper part of chest towards both axillæ, at any time and sometimes lasting hours. During such attacks, sense of suffocation and temporary loss of voice.

Examination (June 1933). - Rather nervous, breathless woman. Thyroid gland not enlarged. Slight if any cyanosis; no clubbing. Pulse 90-100, regular. B.P. 
125/85. Heart; A.B. sixth left space, a.a.1.; forcible. Sounds, I and II all areas. Doubtful diastolic murmur at apex. Pulmonary second sound heard. Lungs, normal. Liver enlarged; no odema. W.R. negative.

Radioscopy.-Heart moderately enlarged as a whole; left border displaced more than right. Pulmonary arc very large and prominent, excessive pulsation. Right P.A. very large; moderate pulsation. L.A. not enlarged (r.o.p.; barium in osophagus). Aortic knob small, scarcely visible (Figs. 6, 11, and 13).

Electrocardiogram.-Normal rhythm; R.A.D. with high voltage. P-R prolonged $(0.22 \mathrm{sec}.) ; \mathrm{T}_{1}$ upright, $\mathrm{T}_{2}$ and $\mathrm{T}_{3}$ inverted.

Course.-Slowly progressive cardiac failure during 1934-35. Orthopnœa, swelling of liver, œdema. Cyanosis only during the last months of life.

Necropsy (April 1935); heart only examined. On opening chest, heart greatly enlarged to right and left; anterior surface formed by R.V. and R.A. P.A. and conus much enlarged; P.A. $4.5 \mathrm{~cm}$. across at its base, the aorta $3 \mathrm{~cm}$. (Fig. 1).

On opening heart, R.V. enormously dilated and its walls hypertrophied, dilatation involving the main cavity and the conus. Tricuspid orifice widened and incompetent. R.A. enlarged and about three times the size of L.A.

In the upper part of the atrial septum above the fossa ovalis, is a circular aperture, $1.5 \mathrm{~cm}$. in diameter. The pulmonary trunk is enormously dilated and its wall thickened, and so are the two main branches. The right P.A. is $3.5 \mathrm{~cm}$. in diameter, the left $2 \cdot 7 \mathrm{~cm}$. The aorta is of small calibre and measures (beyond the left subclavian) $2 \mathrm{~cm}$. in diameter.

Case 4.-K. O., female, aged 28. Married, no children.

History.-No acute rheumatism or chorea. Always said to have a "weak heart "; easily short of breath, and unable to play games. For three months, cough with irregular pyrexia. Admitted to hospital.

Examination (July 1936).- No cyanosis or clubbing. Dyspnœa; œdema of lower limbs. Pulse 110, regular. B.P. 120/70. Heart; A.B. sixth left space, a.a.1. Cardiac pulsation to right of sternum. No thrill. Systolic murmur over mitral area becoming loud and rough over pulmonary area. Second sound scarcely audible. Lungs, crepitations both bases. Liver, slightly enlarged; ascites. Spleen easily felt.

Radioscopy.-Heart moderately enlarged as a whole. Pulmonary arc and conus prominent, pulmonary branches enlarged and intensely pulsating. R.A. very prominent, left cardiac border displaced. Lungs congested.

Electrocardiogram.-Normal rhythm; low voltage curve; R.A.D.

Course.-Continued irregular pyrexia up to $101^{\circ}$. No petechiæ, no clubbing. Repeated blood cultures always sterile. Progressive diminution of hæmoglobin and red cells. Albumin and blood in the urine. Blood urea reached 154, congestive heart failure progressively increased, serous effusions developed, and patient died in October 1936.

Necropsy.-Heart weight $540 \mathrm{~g}$. Great dilatation and conspicuous hypertrophy of R.V., $1 \mathrm{~cm}$. thick; normal L.V. P.A. dilated and thickened, circumference of pulmonary ring $8.5 \mathrm{~cm}$., of aortic ring $5.5 \mathrm{~cm}$. In L.A., extensive confluent vegetations, just contiguous but not involving mitral valve, extending far up its wall. Large interauricular septal defect at the site of the foramen ovale, measuring $3.5 \mathrm{by} 2.5 \mathrm{~cm}$. Great dilatation of R.A. and of the tricuspid ring. Kidneys very small, bright-red spots on surface; cortex mottled on section. Spleen enlarged, two small infarcts. Edema of lungs; effusion in serous cavities; anasarca.

Final Diagnosis.-Subacute bacterial endocarditis. Atrial septal defect.

Case 5.-E. P., female, aged 35. Married, one child.

History.-No acute rheumatism. After childbirth, aged 26, first medically examined and was told she had a "bad heart." No cyanosis in childhood. Six years, effort dyspnœa; two years cyanosis, palpitation and increasing dyspnœa.

Examination (September 1936).-O Obvious cyanosis, no clubbing. Pulse 100, regular. B.P. 100/75. Heart; A.B. in mid-axillary line. No murmurs. Pulmonary second sound accentuated and duplicated. Palpable systolic impulse without thrill over pulmonary area. No signs of failure.

Radioscopy.-Heart greatly enlarged, left border reaches left chest wall; sabotshaped. R.A. prominent. Aneurysmal dilatation of pulmonary arc. Right branch of pulmonary artery enlarged, unduly pulsating. Small aorta. 
Electrocardiogram.-Normal rhythm; R.A.D. with high voltage. P-R full $(0.2 \mathrm{sec}$.$) ; large \mathrm{P}$ waves in leads II and III; QRS $0.12 \mathrm{sec}$.; $\mathrm{T}_{2}$ and $\mathrm{T}_{3}$ sharply inverted.

Course.-Sudden pain developed in left chest, worse on deep breathing. Rigor. Deep cyanosis, severe dyspnœa, pleural friction at left base. Pulmonary infarction was diagnosed, condition became worse, and she died October 1936.

Necropsy.-Heart greatly enlarged and in contact with left chest wall. Whole anterior surface formed by R.A. and R.V. with its conus. L.V. invisible from the front. R.A. dilated and hypertrophied. L.A. only slightly dilated. L.V. of normal size. P.A. huge and its branches greatly dilated and contain ante-mortem clots. Thrombus in bifurcation of left pulmonary branch. Pulmonary infarcts in left upper and right lower lobes. Large circular defect in auricular septum measuring $5 \mathrm{~cm}$.; no other congenital lesion.

Case 6*.-L. T., female, aged 37. Single.

History.-Congenital heart lesion recognized since early childhood. Lifelong dyspnœa and cyanosis. Increasing dyspnœa, with œdema of legs for three months.

Examination.-Cyanosis and orthopnœa; some clubbing. Neck veins distended. Pulse regular. B.P. 130/110. Heart; præcordial bulge. A.B., fifth left space, midaxillary line. Systolic and diastolic thrill with expansile pulsation, at second and third left spaces near sternum. Systolic murmur in mitral area; loud pulmonary systolic murmur, accentuated second sound, and rough diastolic murmur at third left space close to the sternum. Lungs, basal crepitations. Liver, enlarged. W.R. negative.

Radioscopy.-Greatly enlarged heart; left border displaced, R.A. prominent. Aneurysmal dilatation of pulmonary arc. Right branch enlarged and pulsatile. L.A. normal (r.o.p., barium in œsophagus).

Electrocardiogram.-Normal rhythm, R.A.D., ventricular extrasystoles.

Course.-Improvement with rest and digitalis. Four weeks later, sudden death from cerebral embolism.

Necropsy.-Heart greatly enlarged, chiefly R.V. and R.A. Aneurysmal dilatation of P.A., enlargement of its main branches, thickening of the wall, slight atheroma. Pulmonary orifice dilated, incompetent. Right P.A. larger than descending aorta. Relatively small aorta; beyond left subclavian aortic narrowing just admitting finger tip. Ductus arteriosus patent at aortic end, and of conical configuration with a narrow slit at its pulmonary end. The atrial septum contains three apertures, one large and two small. The large is oval, $3 \mathrm{~cm}$. by $2 \mathrm{~cm}$., situated at the upper and posterior part of the septum, just in front of the superior vena cava orifice. The two smaller apertures are below the larger one. The interventricular septum is imperfect at its base having a $2 \mathrm{~cm}$. wide defect opening into the right ventricle just below tricuspid valve, and into the L.V. immediately below the aortic orifice. Aorta communicates with both ventricles. Tricuspid orifice dilated, cusps thickened, calcified deposit between two cusps. L.A. normal. L.V. slightly enlarged and hypertrophied. R.V. much hypertrophied and dilated.

Final Diagnosis.-Defect of atrial septum (persistent ostium secundum); aneurysmal dilatation of pulmonary artery with incompetence of pulmonary valves; defect of ventricular septum; great enlargement of rỉght heart chambers; minimal patency of ductus arteriosus; slight coarctation of aorta.

Case 7.-D. E., female, aged 43. Married, no children.

History.-As a child rheumatic fever; aged 12 and 16, chorea. Aged 27, in hospital with mitral stenosis and heart failure, and again aged 39 when heart was fibrillating. Aged 41, cerebral embolism. The day of admission, sudden severe pain and cramp in left leg.

Examination (June 1937).--Severe dyspnœa. Jugular veins distended. Goitre, tremor, sweating, slight exophthalmos. Pulse; apical rate 180, auricular fibrillation. B.P. 160/100. Left leg and foot pale and cold; no arterial pulsation. Heart; A.B. in a.a.l. Systolic thrill at pulmonary area. Systolic shock over P.A. and conus. Rumbling diastolic murmur at apex. Liver, enlarged.

* The pathological specimen of Case 6, which is in the Heart Hospital Museum, was presented to us by Dr. H. Joules (Joules, 1934) with typical radiographs, and he has kindly approved our redescribing it. 
Radioscopy.-Moderate general enlargement of the heart particularly to left. Prominent pulmonary arc, large right P.A. Aortic knob invisible. Moderate prominence of L.A. (r.o.p., barium in œsophagus). R.V. prominent, aortic window closed by enlarged left P.A. (left oblique).

Electrocardiogram.-Auricular fibrillation. Slight R.A.D.; $\mathrm{T}_{3}$ inverted.

Course.-Improved with rest and digitalis.

August, 1937.- Sudden severe pain in right arm. Tenderness over axillary artery, no pulse felt. Right arm cold from shoulder, hand and forearm powerless, all sensation lost. Heart condition then became worse, with lung congestion and sacral œdema. Because of the persisting pain and danger of gangrene, amputation attempted, but she died during operation.

Necropsy (August 1937).- Heart weight $570 \mathrm{~g}$.; moderately enlarged as a whole. Pulmonary trunk and main intrapulmonary branches much dilated and their walls thickened. R.V. hypertrophied and dilated. R.A. moderately dilated, contains ante-mortem clot adherent to the wall. In the upper part of the foramen ovale there is an oval aperture of about $1 \mathrm{~cm}$. by $0.8 \mathrm{~cm}$. Mitral valve thickened, producing button-hole slit admitting tip of index finger. L.A. moderately enlarged. Aortic, pulmonary and tricuspid valves normal. Infarct at the base of the lower lobe of the left lung with ante-mortem thrombus blocking one main division of the pulmonary branch.

Case 8.-H. F., female, aged 45.

History.-No acute rheumatism. Twenty years, shortness of breath on exertion. Four years, swelling of abdomen and ankles. Eighteen months ago pneumonia, worse since then.

Examination (October 1937).-Severe orthopnœa. Cyanosis, clubbing. Gross œdema of lower limbs. Pulse; apical rate 110, auricular fibrillation. B.P. 110/70. Heart; A.B. fifth left space, 1 in. beyond mid-clavicular line. Systolic thrill and harsh systolic murmur at mitral area. Pulmonary second accentuated. Lungs, crepitations both bases. Liver, enlarged.

Radioscopy.-Patient too ill for this.

Electrocardiogram.-Auricular fibrillation. Low voltage; QRS slurred and notched in all leads.

Course.-Slowly progressive cardiac failure with venous congestion and anasarca. Died January 1938.

Necropsy.-Foramen ovale widely patent $(7 \mathrm{by} 4 \mathrm{~cm}$.). Fenestrated flap of fibrous tissue ( 4 by $2 \mathrm{~cm}$. and $0.05 \mathrm{~cm}$. thick) arising from posterior margin of foramen and continued as a strand of fibrous tissue $(0.1 \mathrm{~cm}$. thick) to centre of anterior margin of foramen. Conspicuous fibrotic thickening, slight shortening and partial fusion of cusps of mitral valve; stenosis $(2 \mathrm{by} 1 \mathrm{~cm}$.) of mitral orifice; fibrous thickening, shortening and focal fusion of chordæ tendineæ of mitral, excepting those of left side of anterior cusp. Slight fibrous thickening without shortening of inferior half of anterior cusp of tricuspid; dilatation of tricuspid ring $(16 \mathrm{~cm}$. circumf.). Considerable dilatation but no hypertrophy of almost spherical L.A. (about $9 \mathrm{~cm}$. diam.); slight opaque white thickening of endocardium. Slight dilatation $(12 \mathrm{~cm}$. circumf.), no gross hypertrophy, but slight hypertrophy of muscle fibres of L.V. Great dilatation (up to $22 \mathrm{~cm}$. circumf.), gross hypertrophy (up to $0.6 \mathrm{~cm}$. thick) and hypertropthy of muscle fibres of R.V. Focal fibrosis of myocardium of both ventricles and slight fibrotic thickening of pericardium. Great dilatation (anterior surface $16 \mathrm{~cm}$. long, $12 \mathrm{~cm}$. across), no gross hypertrophy, but great hypertrophy of scanty muscle fibres of R.A.; severe fibrosis of myocardium; slight opaque white elastic hyperplasia of endocardium, fibrous and elastic thickening of pericardium. Clear yellow pericardial effusion ( $3 \mathrm{oz}$.). Great dilatation of P.A. $(10 \mathrm{~cm}$. circumf. just above valves) and of all its branches within lungs (up to $4.6 \mathrm{~cm}$. circumf.). A few fatty flecks of atheroma in hypertrophied intima of P.A. Less dilatation of branches of pulmonary veins. Slightly purulent mucous exudate in trachea and bronchi. Congestion, slight induration, slight intra-alveolar hæmorrhage and hæmosiderosis and slight œdema of lungs. Collapse of lower anterior half and lower posterior angle of left lower lobe. Considerable bronchopneumonia in left lower lobe. Clear yellow pleural effusions $(16 \mathrm{oz}$. right, 4 oz. left). Clear yellow peritoneal effusion ( 3 oz.). Pitting œdema of feet, legs, thighs, and lumbar region. 
Final Diagnosis.-Bronchopneumonia. Chronic heart failure. Mitral stenosis. Chronic rheumatic endocarditis. Atrial septal defect at site of fossa ovalis. (Lutembacher's syndrome.)

Case 9.-E. G., male, aged 33.

History.-No acute rheumatism or chorea. Blue since birth. Attended school, but played no games. Light work since leaving school. Frequent epistaxis; otherwise well until aged 23, when twice admitted to hospital for dyspnœa. Hæmoptysis few days before second admission.

Examination (November 1936).--Undersized; kyphosis. Deep cyanosis with clubbing. Pulse, 100, auricular fibrillation. B.P. 105/95. Heart; bulging of the chest wall to left of sternum. A.B., sixth left space, a.a.l. Rumbling diastolic murmur at apex. Harsh systolic murmur at pulmonary area. Lungs; bilateral basal crepitations. Liver; enlarged, pulsating. Blood count; hæmoglobin 160 per cent, red cells 6.9 million.

Radioscopy.-Huge heart extending to left chest wall. Enlargement and hypertrophy of R.V., R.A., and L.A. P.A. invisible. Small aorta. Right hilus hidden behind dilated R.A. (Fig. 16).

Electrocardiogram.- Auricular fibrillation. Right bundle branch block.

Course.-Admission to hospital in 1937, 1938, and 1939, for progressively increasing heart failure with deep cyanosis, orthopnœa, large pulsating liver, and general œdema. Died November 1939.

Necropsy.-Huge heart, weight $930 \mathrm{~g}$. Enormous R.V. and conus forming a large square-shaped sac. R.A. also grossly enlarged. Aorta small. P.A. normal. L.V. invisible from front (Fig. 4).

On opening the heart the R.V. forms an enormous cavity separated from the huge conus by a very thick muscular band. Wall of R.V. little if at all thickened. Tricuspid orifice dilated (8 to $9 \mathrm{~cm}$. in diameter). R.A. very large, cavity takes whole fist.

In the atrial septum in the position of the foramen ovale is a large, obliquelyplaced aperture, 2 by $3 \mathrm{~cm}$. in diameter and admitting the tips of two fingers. Left auricular cavity little if at all enlarged. Mitral valve rigid, calcareous, cusps fused and stenosed, orifice admits the tip of one finger. L.V. normal; its wall much thicker than that of the R.V.

Case 10.-R. S., female, aged 33. Married, two children.

History.-Alleged rheumatism 7 years ago, not previously. Admitted to hospital as "cardiac failure, amenorrhoa (? pregnancy)."

Examination (January 1938).- - High colour, but no cyanosis. Pulse 130, regular, small volume. Edema of ankles. Heart; A.B., sixth left space, greatly enlarged. Systolic murmur and faint diastolic murmur in mitral area. Lungs, basal crepitations. Liver, enlarged with ascites.

Radioscopy.-Patient too ill for this.

Electrocardiogram.-Auricular flutter (2:1); at times fibrillation.

Course.-The diagnosis was mitral stenosis, auricular fibrillation, congestive heart failure. Operation for hysterotomy and sterilization. Died during the operation (February 1938).

Necropsy.-Viewed externally, great enlargement of the heart affecting mainly R.A. and R.V., the latter forming the entire apex and most of the left border. P.A. greatly dilated, $4.5 \mathrm{~cm}$. in diameter; aorta small, $2.3 \mathrm{~cm}$. in diameter. On opening the heart, R.V. much dilated with little if any hypertrophy. Great dilatation of R.A. and of tricuspid orifice which admits four fingers. There is a large oval defect in the atrial septum, $5 \mathrm{~cm}$. by $3.5 \mathrm{~cm}$. in diameter, its long axis being vertical. A rudimentary atrial septum surrounds the aperture except at its upper margin; anteriorly and below is a firm ridge $1 \mathrm{~cm}$. wide, and posteriorly a thin membrane $0.5 \mathrm{~cm}$. wide. The L.A. about half the size of the right; the L.V. not enlarged. Mitral orifice stenosed and of the button-hole type; the cusps thickened and the chordæ thickened and shortened. Descending aorta small, $1.3 \mathrm{~cm}$. in diameter; right P.A. large, $2 \cdot 7 \mathrm{~cm}$. in diameter (Fig. 5). 